Prepared for the U.S. Department of Energy under Contract DE-AC05-76RL01830

\title{
Roadmap to Monitor Data Collected during the WSCC Breakup of August 10, 1996
}

\section{JF Hauer \\ JW Burns}

June 2010

\section{Pacific Northwest}

NATIONAL LABORATORY

Proudly Operated by Battelle Since 1965 


\title{
DISCLAIMER
}

This documentation was prepared as an account of work sponsored by an agency of the United States Government. Neither the United States Government nor any agency thereof, nor Battelle Memorial Institute, nor any of their employees, makes any warranty, express or implied, or assumes any legal liability or responsibility for the accuracy, completeness, or usefulness of any information, apparatus, product, or process disclosed, or represents that its use would not infringe privately owned rights. Reference herein to any specific commercial product, process, or service by trade name, trademark, manufacturer, or otherwise does not necessarily constitute or imply its endorsement, recommendation, or favoring by the United States Government or any agency thereof, or Battelle Memorial Institute. The views and opinions of authors expressed herein do not necessarily state or reflect those of the United States Government or any agency thereof.

\author{
PACIFIC NORTHWEST NATIONAL LABORATORY \\ operated by \\ BATTELLE \\ for the \\ UNITED STATES DEPARTMENT OF ENERGY \\ under Contract DE-AC05-76RL01830 \\ Printed in the United States of America \\ Available to DOE and DOE contractors from the \\ Office of Scientific and Technical Information, \\ P.O. Box 62, Oak Ridge, TN 37831-0062; \\ ph: (865) 576-8401, fax: (865) 576-5728 \\ email: reports@adonis.osti.gov \\ Available to the public from the National Technical Information Service, \\ U.S. Department of Commerce, 5285 Port Royal Rd., Springfield, VA 22161 \\ ph: (800) 553-6847, fax: (703) 605-6900 \\ email: orders@ntis.fedworld.gov \\ online ordering: http://www.ntis.gov/ordering.htm
}


PNNL-19459

\section{Roadmap to Monitor Data Collected during the WSCC Breakup of August 10, 1996}

JF Hauer

JW Burns ${ }^{(a)}$

June 2010

Prepared for

U.S. Department of Energy

under Contract DE-AC05-76RL01830

Pacific Northwest National Laboratory

Richland, Washington 99352

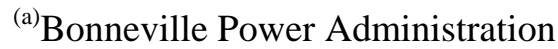

Vancouver, Washington 98666-0491 



\section{Summary}

On August 10, 1996, progressive weakening of the Western Interconnection led to a cascading power outage that broke the system into four disconnected islands and affected some 7.5 million customers. The breakup was an important event, with major implications for the management of large power systems $[1,2,3]$. Operational records for this breakup continue to provide general insights into power system behavior, and the data for dynamic behavior provide an attractive test bed for new methodologies that extract operator information from ongoing system activity.

The monitor records collected on August 10, 1996 were extensive, and they have been distributed in a variety of forms. The work reported here is part of an ongoing effort to draw together and preserve the original data, and to supplement them with later information on items such as time stamp errors, filtering effects, and various other discrepancies that are important to correct interpretation of the data. The objective of this report is to provide a "roadmap" for navigating the data, and to explain the context in which the data were obtained and/or processed.

Future users of the data discussed here should be aware of the following:

A. Most of the data were collected on a central monitor located at BPA's Dittmer Control Center. Called a PPSM (portable power system monitor), it continuously recorded signals from analog transducers located at 96 sites around the BPA service area. Records in the event archive extend from 11:48:00 to 11:53:50, and from 12:58:00 to 16:04:40. These times are nominal based upon the PPSM clock. Results shown later indicate that this clock lagged timing of the Malin phasor measurement unit (PMU) by 5 seconds.

B. Phasor data were collected from four PMUs located around the Western Interconnection. PMU records in the event archive are brief "event files" triggered by the final system breakup at 15:48:51. Timing of the four PMUs appears to be consistent, but this has not been rigorously confirmed.

C. The transducers providing signals to the Dittmer PPSM were of many different types. Their dynamic response varied widely, and the signals were also affected by the microwave channels carrying them to the Dittmer PPSM. These factors produced signal lags that ranged from negligible to a full half-second in the most severe case.

D. Data from the Malin PMU should be used selectively. Although the device continued to operate after the breakup, voltage at the device had reduced to essentially zero, and data beyond that time should not be considered valid.

E. Many subsets of PPSM data for this event have been circulated among interested parties. In some cases, the data have been low pass filtered to reduce extraneous noise, and in a very few cases, the reference time has been adjusted (by 5 seconds) to match that of the Malin PMU. Graphics in this report can be used to determine whether such modifications are present in a specific data set.

F. Prony analysis results in Kosterev et al. [3] differ somewhat from those in Hauer 1997 [4] and in Table H1 of Hauer's commentary [3]. This is partly attributable to use of slightly different analysis windows. However, it appears that the Prony software used for the BPA analysis was an older PSAPAC version that processed one signal at a time [2,5], rather than multiple signals in tandem (as in the PNNL version). None of these documents provides full processing details, so their results may be difficult to replicate exactly. 
G. When a PMU is installed parallel to an analog transducer, a comparison of their outputs can be used to determine their relative response, and then to refine archival data acquired from the latter device [6]. The report includes some cross-calibrations against PMU data collected in the WSCC system tests on June 7, 2000. Findings are that response of the enhanced analog transducers at Malin exactly match that of the Malin PMU, but that the conventional MW transducers at Celilo 230 and Celilo 500 (called the "existing" and "expansion" converters in [2] lag the corresponding PMUs by roughly 0.42 second and 0.26 second, respectively. This translates to 35 degree and 22 degree corrections to the $0.23 \mathrm{~Hz}$ mode shape plot in [2].

The citation of specific commercial products or manufacturers within this document is for research purposes only and does not imply endorsement or recommendation of that equipment. 


\section{Contents}

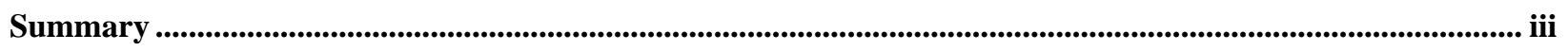

Introduction

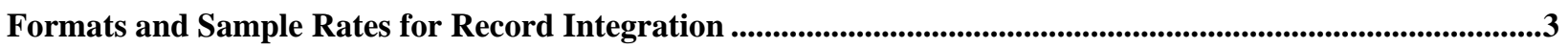

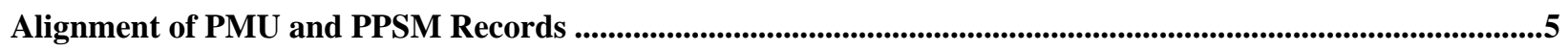

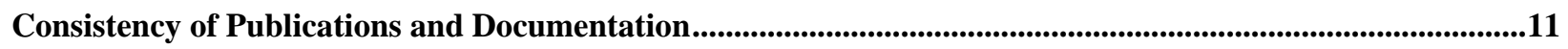

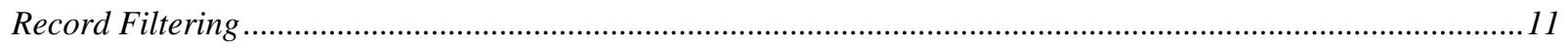

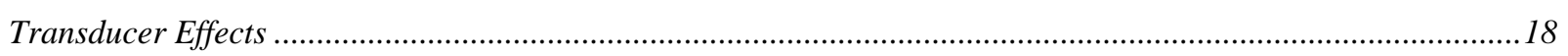

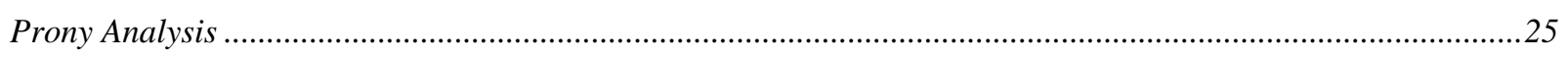

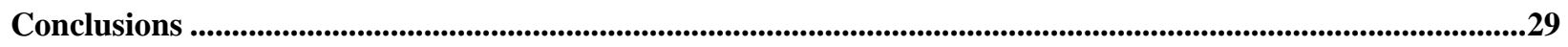

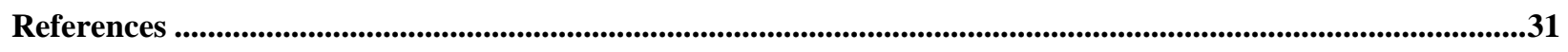

Appendix A. Modal Trends for the WSCC Breakup of August 10, 1996 [4] .....................................................35 


\section{Figures}

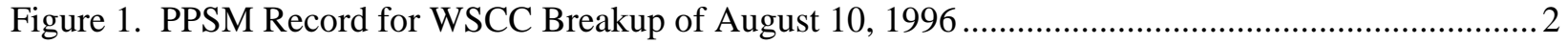

Figure 2. Angle Transients for WSCC Breakup on August 10, 1996 ................................................... 4

Figure 3. Frequency Response Characteristics of Malin Transducers on August 10, 1996 ......................5

Figure 4. Alignment Check \#1 on PMU Records .............................................................................. 6

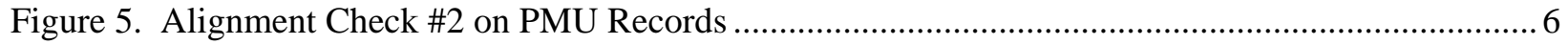

Figure 6. Performance Degradation of Malin PMU at System Breakup .................................................... 7

Figure 7. Performance Degradation of Malin PMU at System Breakup (detail) ...................................... 7

Figure 8. Performance of Malin PMU just Before System Breakup (detail) ........................................... 8

Figure 9. Alignment Check \#1 on Dittmer \#1 PPSM Data (10 sps) ....................................................... 8

Figure 10. Alignment Check \#2 on Dittmer \#1 PPSM Data (10 sps) ..................................................... 9

Figure 11. Corrected Alignment of Dittmer \#1 PPSM Data (30 sps) ................................................... 10

Figure 12. Gain Characteristics for Low Pass Filters LP1 and LPH.................................................. 11

Figure 13. Phase Characteristics for Low Pass Filters LP1 and LPH .................................................. 12

Figure 14. Use of LP Filters to Enhance Visibility of Low Frequency Activity in PPSM Records.......... 13

Figure 15. Use of LP Filters to Enhance Visibility of Low Frequency Activity in PPSM

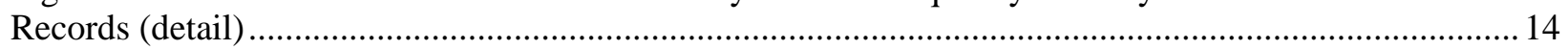

Figure 16. Smoothing Effect of LP1 on the PPSM Signal for Malin-Round Mountain \#1 MW............... 15

Figure 17. Raw PPSM Data for MW on the Celilo Expansion Converter of the PDCI …..................... 15

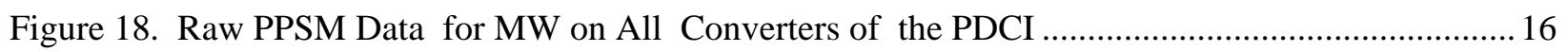

Figure 19. Effects of LP1 on the PPSM Signal for Total PDCI MW at Sylmar...................................... 16

Figure 20. Gain Characteristic for Bandpass Filter BP1 …................................................................ 17

Figure 21. Use of Bandpass Filter to Enhance Visibility of Small Signal Activity in PPSM Records ..... 17

Figure 22. Use of Absolute Value of Bandpassed Signal to Measure Activity .......................................18

Figure 23. Inconsistent Signals for NW Generation Trip Event on April 18, 2002 ............................... 19

Figure 24. Spectra and Coherency of PPSM Signal Relative to PMU Signal ......................................... 20

Figure 25. Virtual Frequency Response of PPSM Signal to PMU Signal ................................................ 20

Figure 26. Spectra and Coherency of PPSM Signal Relative to PMU Signal ....................................... 21

Figure 27. Virtual Frequency Response of PPSM Signal to PMU Signal .............................................. 21

Figure 28. Spectra and Coherency of PPSM Signal Relative to PMU Signal ......................................... 22

Figure 29. Virtual Frequency Response of PPSM Signal to PMU Signal ................................................. 22

Figure 30. PDCI Transducer Responses to Single-Mode Probing on June 7, 2000 ..............................23 
Figure 31. PDCI Transducer Responses to Single-Mode Probing on June 7, 2000 (detail).....................24

Figure 32. Validation of PPSM Timing vs. PMU ……......................................................................... 24

Figure 33. Validation of PPSM timing vs. PMU (detail) .......................................................................... 25

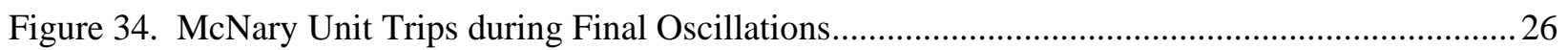

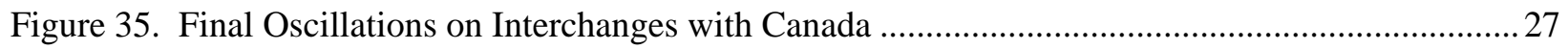

Figure 36. PACI Response to Brake Insertion of 10:52:19 on August 10, 1996 .................................. 35

Figure 37. PACI Response to Trip of John Day-Marion Line, August 10, 1996 .................................... 36

Figure 38. Oscillation Modes Visible in the Chief Joseph Brake Insertion at 10:52 PDT on

August 10, 1996 37 


\section{Tables}

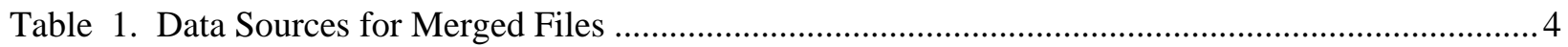

Table 2. Prony Results for 0.3 Hz Probing Pulse (Trange=[1.7 8.4] seconds, except [2.1 8.8] for

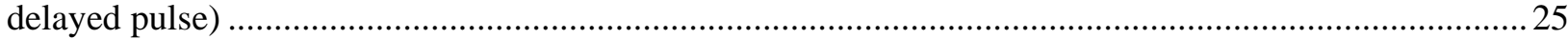

Table 3. Summary of Observed Parameters for the North-South Mode.................................................38 


\section{Introduction}

Most of the data for wide area dynamics on August 10, 1996 were collected on the following monitor systems operated by the Bonneville Power Administration (BPA) and by the Arizona Public Service Co. (APS):
BPA portable power system monitor (PPSM) Units
20 samples/second
BPA phasor measurement units (PMUs)
30 samples/second
APS phasor measurement units
12 samples/second

While all of these devices were GPS synchronized, it is always necessary to validate the time stamps.

Data were also collected on various Power Technologies Inc. (PTI) dynamic system monitor (DSM) units, fault recorders, supervisory control and data acquisition (SCADA) systems, and local monitors of various types. A full inventory of these devices and the records collected does not seem to be readily available.

BPA's primary monitor was PPSM unit DIT1 at the Dittmer control center. This device was installed there in support of model validation work coordinated by the Western Systems Coordinating Council (WSCC) System Oscillations Work Group (SOWG) [7]. The Dittmer PPSM performed continuous recording of 96 signals across the BPA service area, based upon microwave access to analog transducers. These data were available throughout the August 10 event, and the records were directly useful for determining the course of action immediately following the breakup. Figure 1 is one of many wellknown graphics derived from the Dittmer PPSM for the event. As indicated in the caption, the data have been smoothed with a low pass filter to reduce measurement noise. It is believed that the filter was set to $0.5 \mathrm{~Hz}$, but this has not been fully verified.

Event records from the Dittmer PPSM were promptly sent to Pacific Northwest National Laboratory (PNNL) for integration and analysis. A great deal of material was exchanged rather quickly. The origin and the processing for some of the report materials are difficult to establish at this late date, and it is likely that other analysts working with different tools would produce somewhat different quantitative results. PNNL documentation for this stage of the effort seems to be limited to communication between J Hauer and WA Mittelstadt, August 28, $1996^{1}$ and various drafts of Hauer 1997 [4]. Prony analysis results in [2] resemble those in [4], but the analysis windows and the modal estimates are slightly different. Both documents are short on details regarding processing controls and the exact software in use.

Phasor data were collected locally on PMUs located at Colstrip, Grand Coulee, Malin, and Pinnacle Peak (near Phoenix, AZ). Data from the BPA PMUs were provided on August 20 by Ken Martin², and data from the APS PMUs were provided by Doug Selin upon later request.

All data operations described here were performed with the BPA/PNNL Dynamic System Identification (DSI) Toolbox $[8,9,10]$.

\footnotetext{
${ }^{1}$ Description of monitor data collected for the WSCC Breakup on August 10, 1996, J.F. Hauer, WAMS communication to WA Mittelstadt, August 28, 1996.

${ }^{2}$ Email description of BPA PMU data for the WSCC breakup of August 10, 1996, K.E. Martin, WAMS communication, August 20, 1996.
} 
Malin-Round Mountain \#1 MW

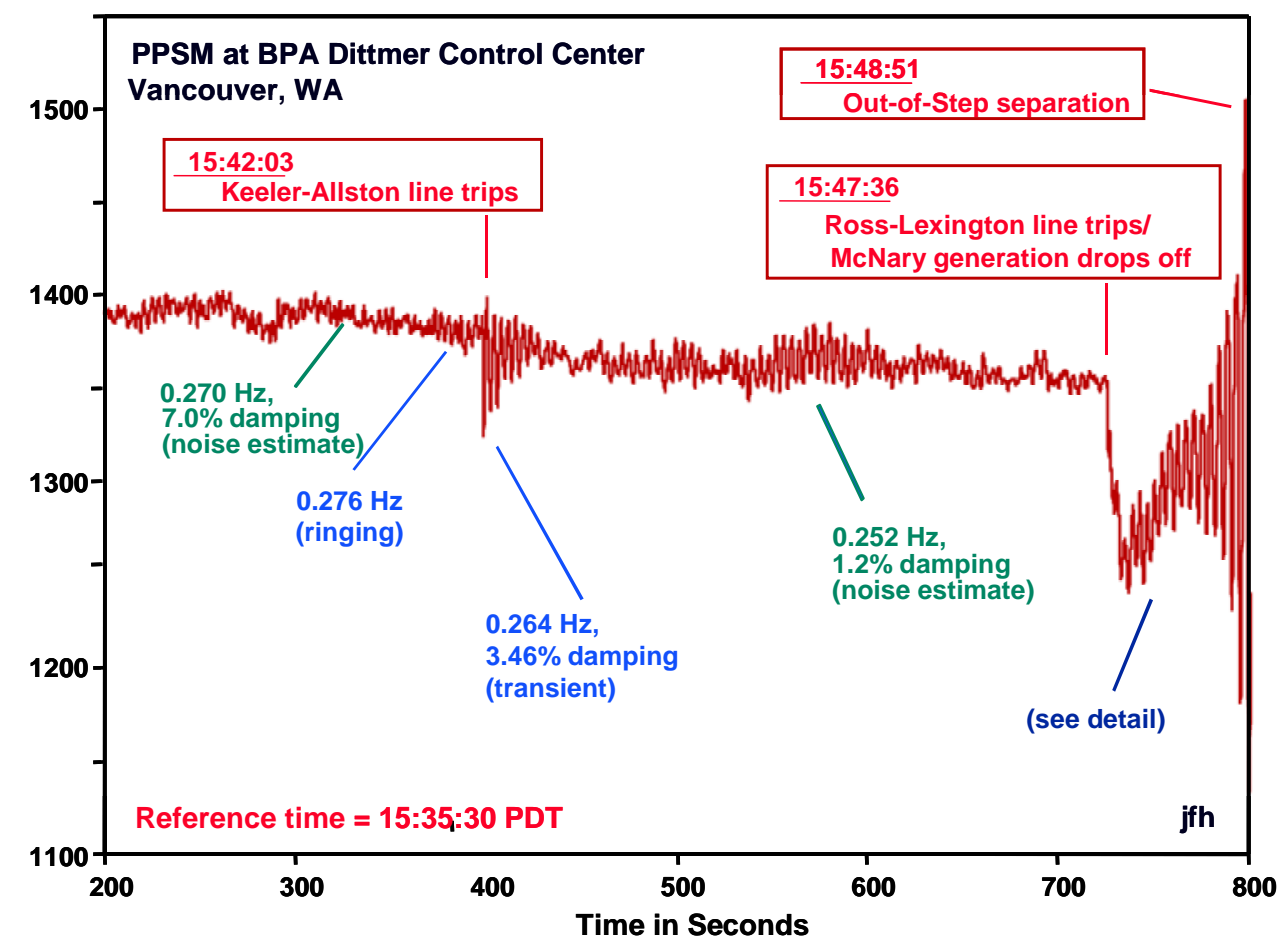

Figure 1. PPSM Record for WSCC Breakup of August 10, 1996

(a low pass filter has been used to reduce noise) 


\section{Formats and Sample Rates for Record Integration}

Raw data obtained from each of the primary recording systems were obtained in a different format. PPSM data were provided in a native format unique to that device. PMU data were embedded within a number of rather large Excel files that also contained high quality graphics. The original Excel files were processed through the DSI Toolbox as formatted text and then translated into more general formats. The first is a MATLAB format (PSMT), which is standard to the DSI Toolbox. The second is a tabbed-ascii format that is used with swing export (SWX) data obtained from the General Electric power systems analysis software (PSLF/PSDS) simulation program [11]. These formats are readily accepted by MATLAB and Excel, respectively.

Record integration with the DSI Toolbox is a two-step process. The first step translates the initial records into PSMT format, and the second merges multiple PSMT files into one. The correlation between the data sources and the "merge files" is shown in Table 1 . The overall process commonly involves time stamp editing plus data resampling.

In this case, each of the three recording systems has a different recording rate. The values (20/30/12 samples per second - sps) are such that acceptable integration of the records cannot be achieved through decimation alone. 12 sps PMU records from APS can be merged with 30 sps PMU records from BPA if the data are decimated to 6 sps, and the 20 sps PPSM data can be directly integrated with just the PMU data from BPA or APS at final data rates of 10 sps or 4 sps, respectively. Direct integration of the PPSM data with all of the PMU data would require decimation to 2 sps, which would incur an unacceptable loss of information.

General integration can achieve adequate final rates through less direct means, with the slower records "upsampled" to higher sample rates and then decimated to the overall final rate. A variety of integrated files have been produced in this manner, usually with upsampling to 60 sps followed by decimation to 30 sps [12].

The PMU records collected by BPA are fairly short, and their overlap with the APS records is brief. Even so, the integrated PMU records provide a useful cross section of re-separation phase angles across the power system plus a view of the initial transients (see Figure 2 and other figures to follow). Because of their length, the APS records provide a good overview of conditions in the southwest island for approximately 9 minutes beyond the NE/SE separation circa 1548:54. These records can be integrated with those of the Dittmer PPSM, for the entire time period, if the need arises.

Graphical comparison of the various PMU records revealed no significant timing discrepancies, and the PMU timestamps are assumed to be correct (or nearly so). However, graphical comparison of BPA's PPSM and PMU records indicates that timing for PPSM unit Dittmer \#1 was 5 seconds late for California-Oregon Interconnection (COI) tripping. Alignment with the PMU records was achieved by reducing the time stamp value in the SWX and PSMT files derived from the raw DIT1 records ${ }^{3}$. More details of this are shown in the next section.

\footnotetext{
${ }^{3}$ Such data modifications are noted in the case comments module for PSMT data, and in the comments header for SWX data. Data users should be alert to such imbedded information.
} 
Table 1. Data Sources for Merged Files

Merge File
MF01
MF02
MF03
MF04
MF05

Data Source

BPA PMU at Colstrip

BPA PMU at Grand Coulee

BPA PMU at Malin

APS PMU at Pinnacle Peak

BPA PPSM unit at Dittmer Control Center

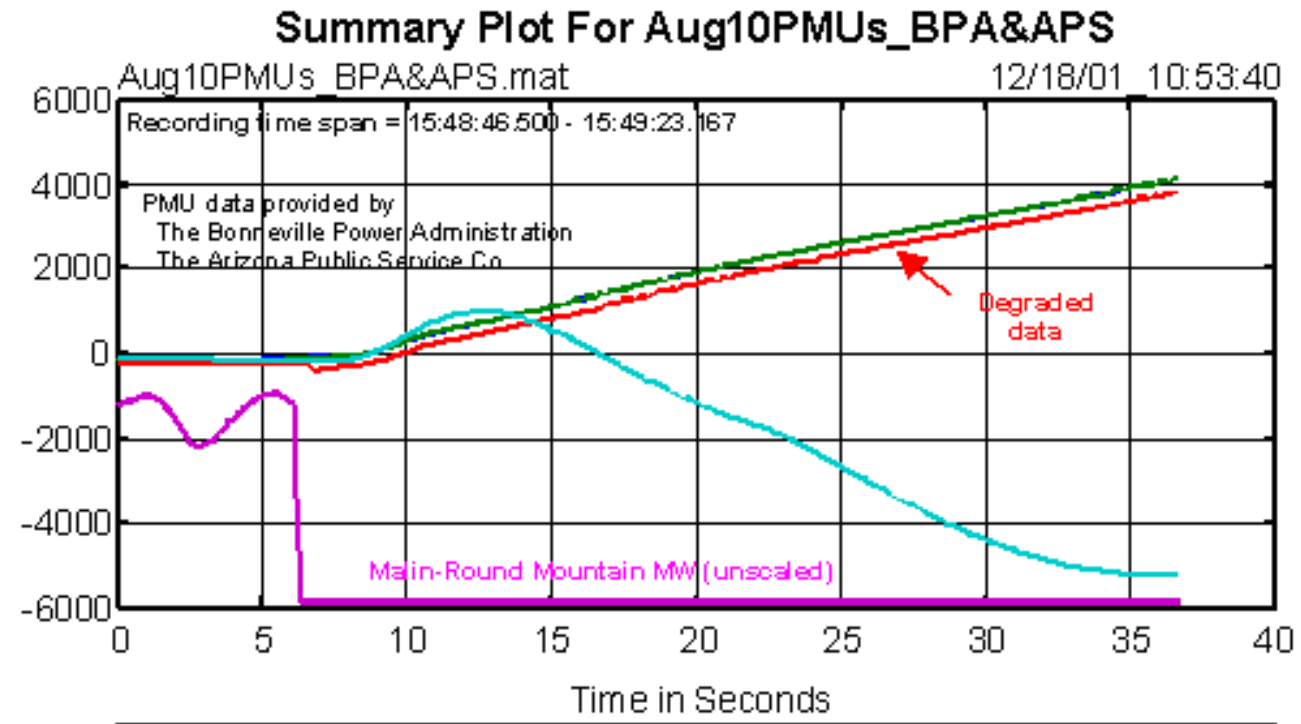

\begin{tabular}{|lcc|}
\hline Colstrip Bus Voltage & VingL & MF01 \\
Grand Coulee Bus & VAngL & MF02 \\
Malin Bus Voltage & VAngL & MF03 \\
Pinnacle prs Bus & VingL & MF04 \\
\hline
\end{tabular}

Figure 2. Angle Transients for WSCC Breakup on August 10, 1996 


\section{Alignment of PMU and PPSM Records}

Monitor signals from Malin were provided by a Macrodyne 1690M PMU, six enhanced analog transducers, and an assortment of conventional analog transducers. Nominal bandwidths for these devices are $7 \mathrm{~Hz}, 20 \mathrm{~Hz}$, and $2 \mathrm{~Hz}$, respectively; their response characteristics are approximately as shown in Figure 3. Bandwidth of the microwave channels carrying signals from the enhanced analog transducers to the Dittmer PPSM is believed to have been about $12 \mathrm{~Hz}$.

Short records and geographic distances preclude precise examination of timing differences among the various PMUs. However, the comparisons in Figure 4 and Figure 5 suggest that such differences are (at worst) small.

Frequency data from the Malin PMU are not included in the timing comparison of Figure 5. Figure 6, and later Figure 9, show that voltage at the Malin PMU declined to something very near to zero at the onset of the breakup. Although the instrument continued to provide outputs beyond that time (Figure 2), they must be regarded as suspect. Figure 7 shows that the instrument level frequency signal during that time was not consistent with the frequency estimated from voltage angle. Figure 8, on the other hand, shows that the two were consistent just before that time.

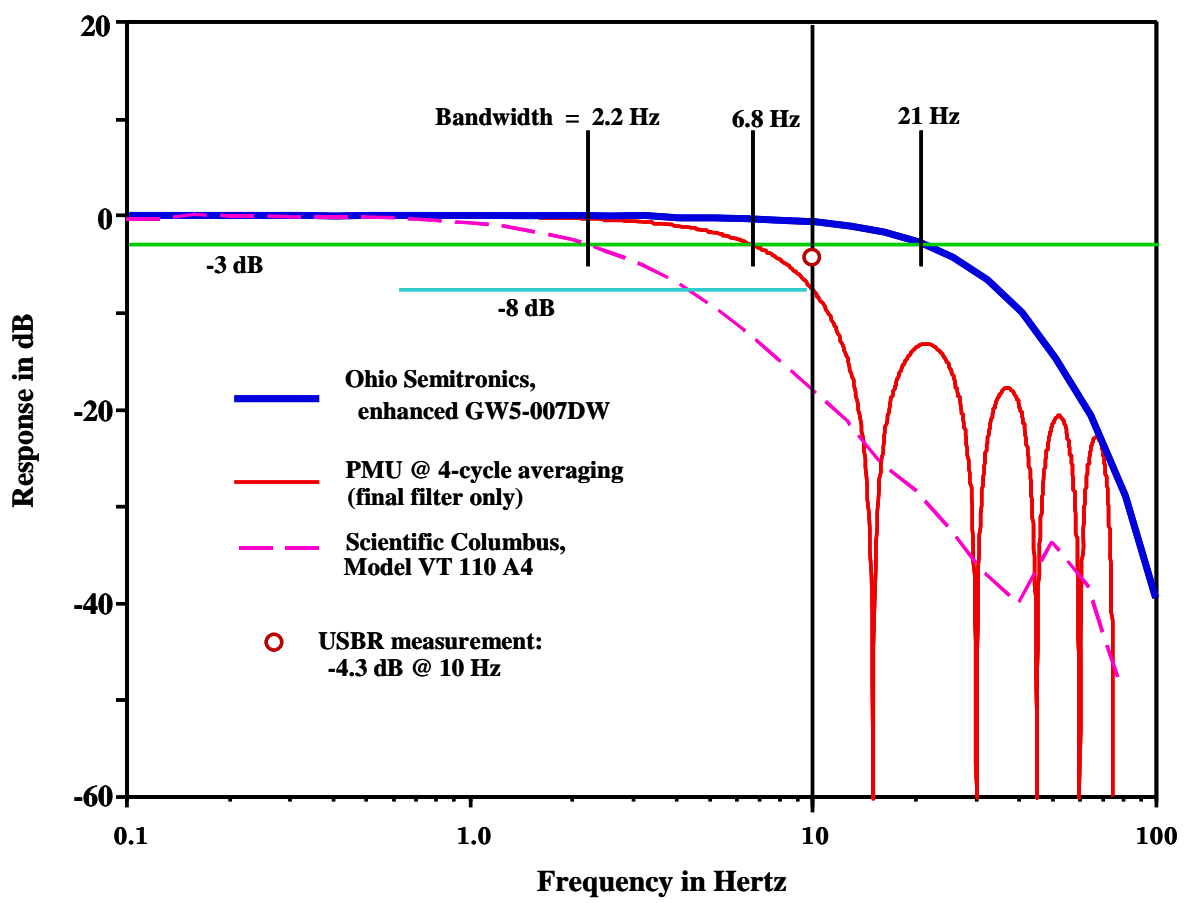

Figure 3. Frequency Response Characteristics of Malin Transducers on August 10, 1996 


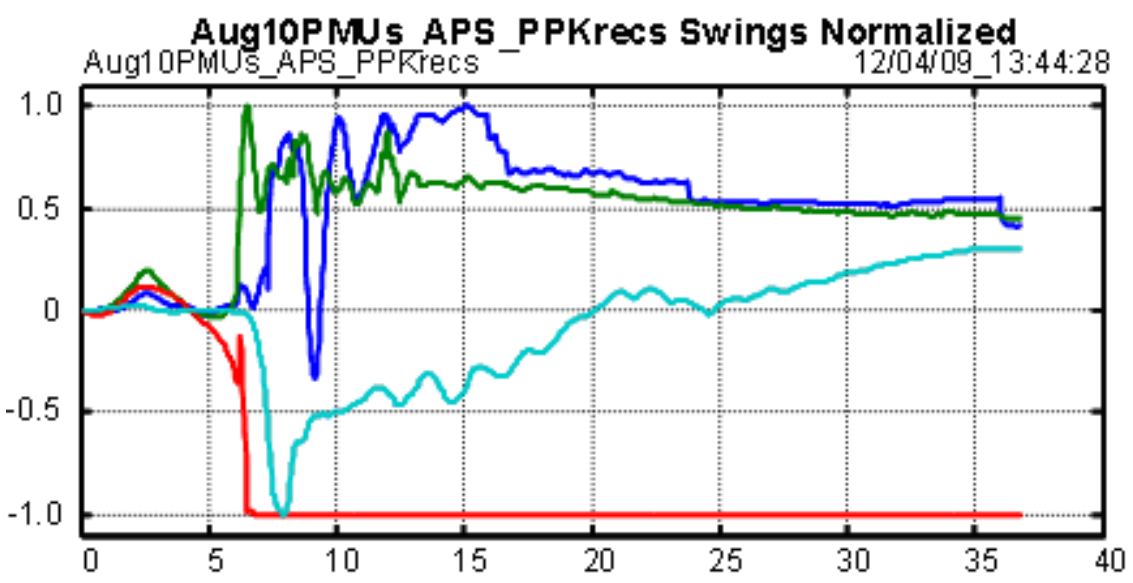

Time in Seconds since 10-Aug-1996 22:48:46.500

\begin{tabular}{|llll|}
\hline & Colstrip Bus Voltage & Mag & MF01 \\
& Grand Coulee Bus & Mag & MF02 \\
Malin Bus Voltage & Mag & MF03 \\
Minnacle Pk Bus & Mag & MF04 \\
\hline
\end{tabular}

Figure 4. Alignment Check \#1 on PMU Records

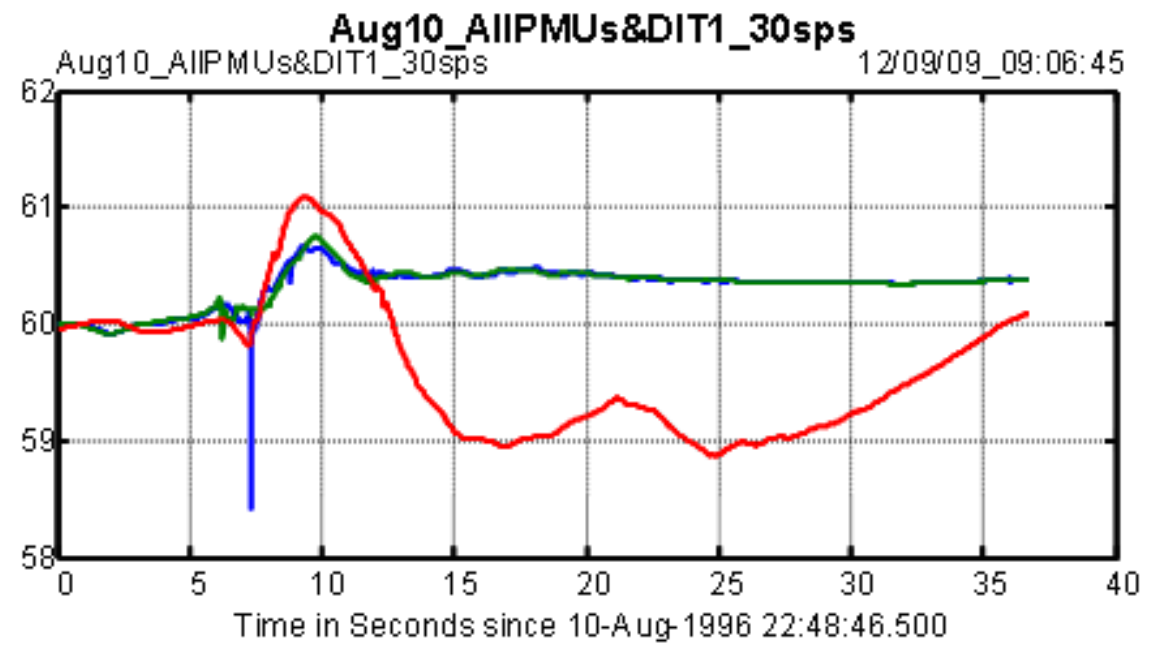

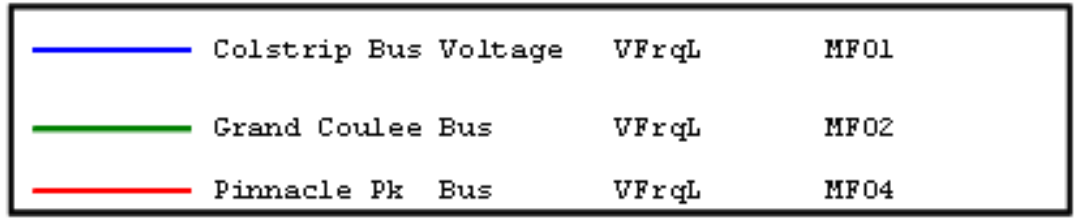

Figure 5. Alignment Check \#2 on PMU Records 


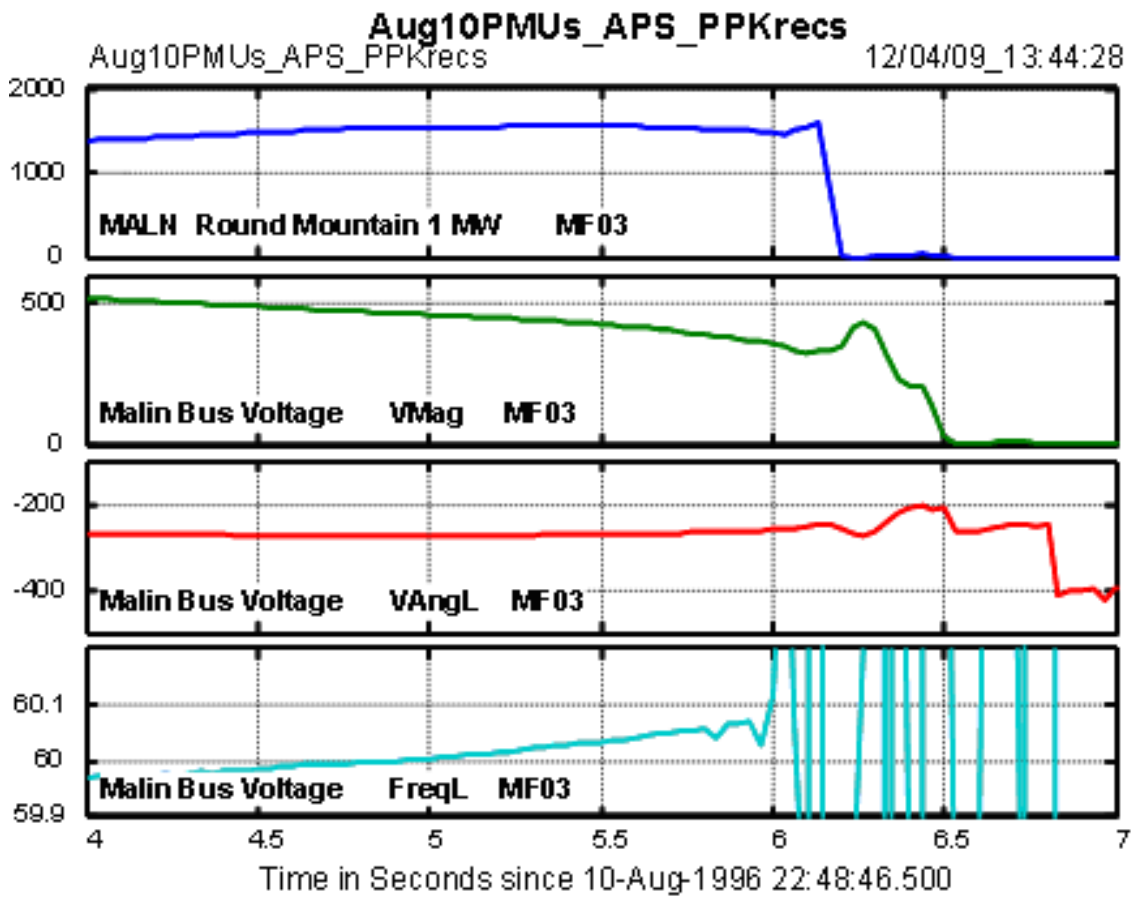

Figure 6. Performance Degradation of Malin PMU at System Breakup

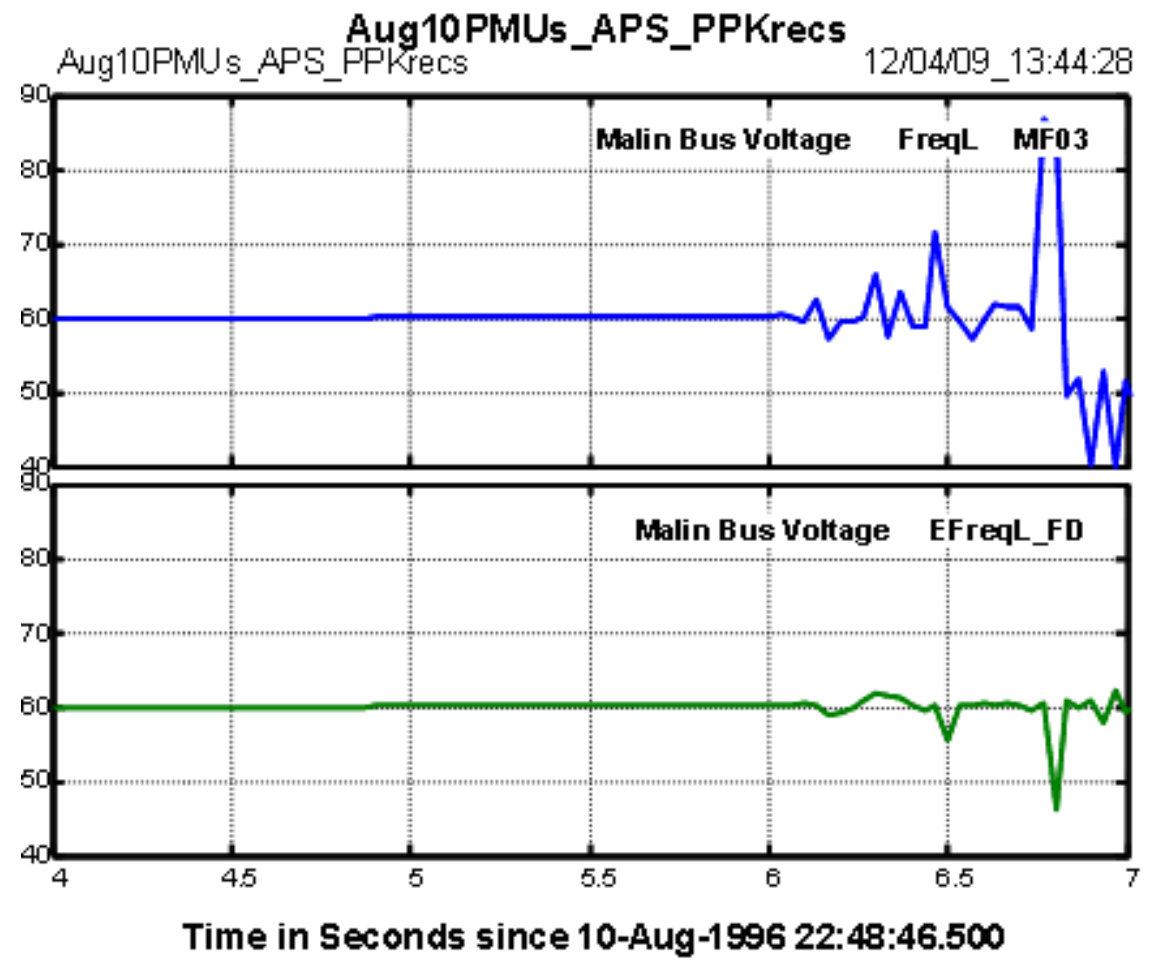

Figure 7. Performance Degradation of Malin PMU at System Breakup (detail) 

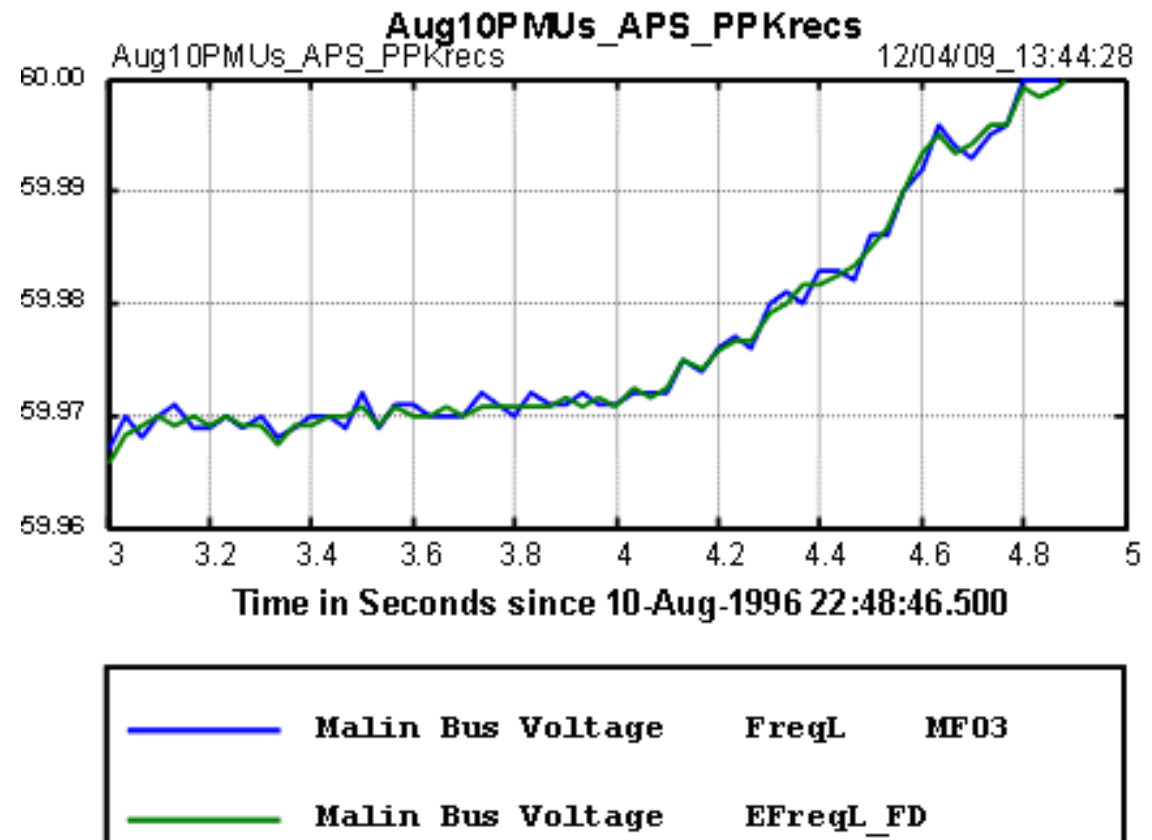

Figure 8. Performance of Malin PMU just Before System Breakup (detail)

Summary Plot For Aug10_BPA_PhUs\&DIT1

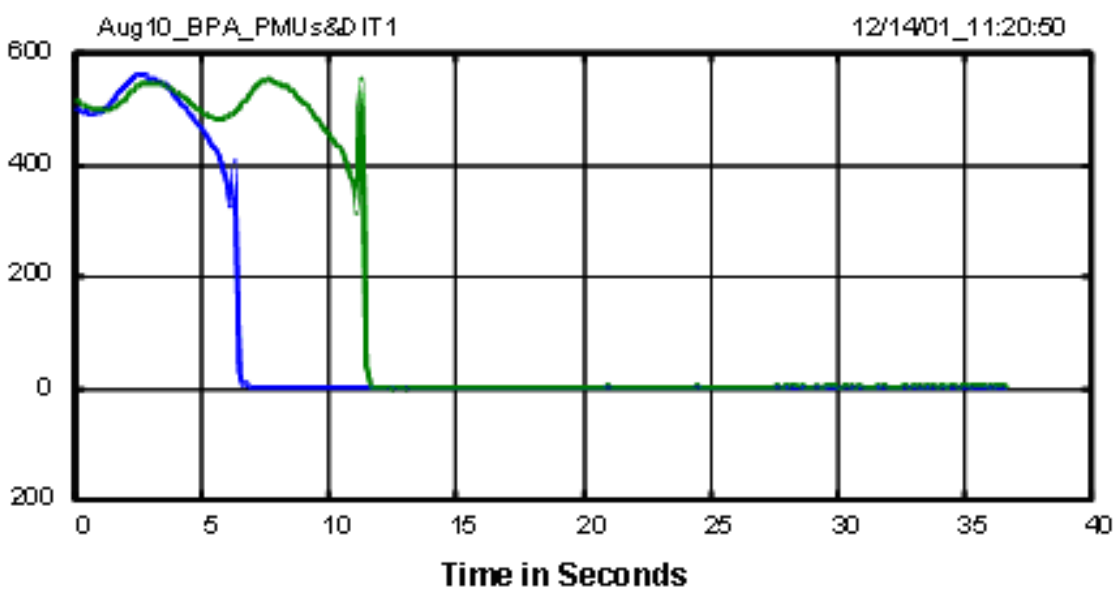

Malin Bus Voltage vag (PMU)

Malin-Round Mountain \#1 kV (PPSM)

Figure 9. Alignment Check \#1 on Dittmer \#1 PPSM Data (10 sps) 
Figure 9 and Figure 10 use strong transients early in the breakup to examine alignment of BPA's PPSM and PMU records. The records were integrated with direct decimation to 10 sps, thus avoiding more complex operations that might have raised uncertainties concerning possible sources of misalignment.

As discussed above, there are definite uncertainties regarding performance of the Malin PMU during this period. However, waveforms from the two data sources are very similar in both figures. Relative to PMU timing, both figures indicate that records for PPSM unit Dittmer \#1 are 5 seconds late for COI tripping. Alignment with the PMU records was achieved by reducing the time stamp value in the SWX and PSMT files derived from the raw DIT1 records. Figure 11 represents integration of the PPSM records with all PMU records, with PPSM timing adjusted and all data resampled for a final rate of 30 sps.

Summary Plot For Aug10_BPA_PhIs\&DT1

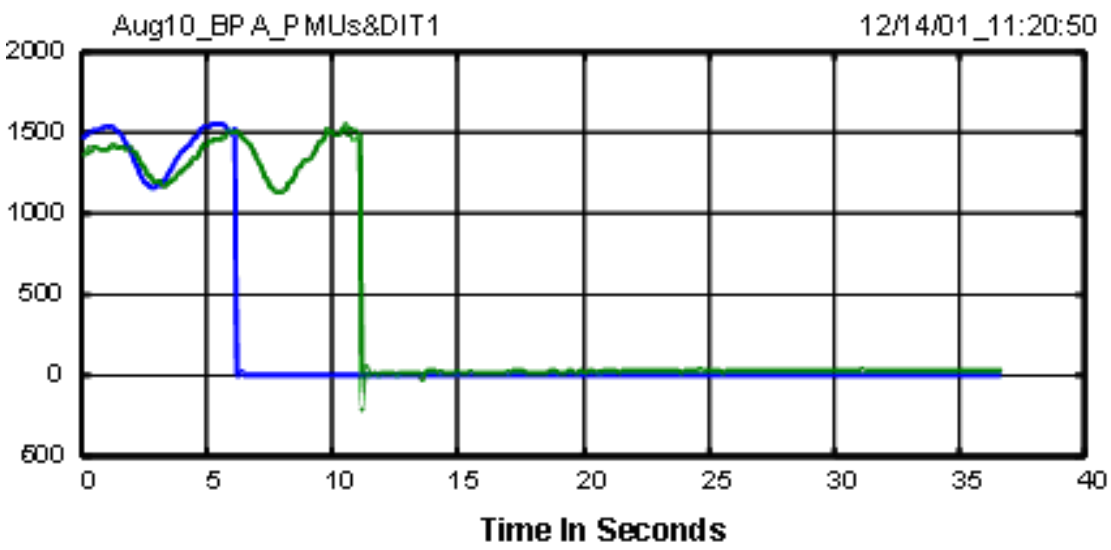

MALW Round Mountain 1 MW

(PMI)

Malin-Round Mountain \#1 MW (PPSM)

Figure 10. Alignment Check \#2 on Dittmer \#1 PPSM Data (10 sps) 
Summary Plot For Aug 10_AllPhUs8dIT1_30sps

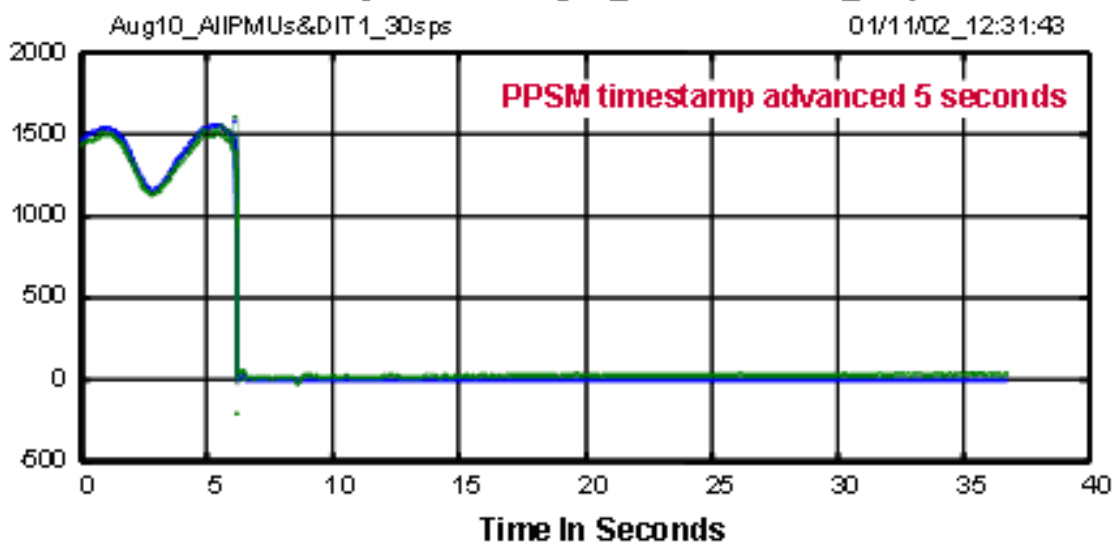

MALW Round Mo untain 1 MW

(PMU)

Malin-Round Mountain \#1 MW

(PPSM)

Figure 11. Corrected Alignment of Dittmer \#1 PPSM Data (30 sps) 


\section{Consistency of Publications and Documentation}

\section{Record Filtering}

Most of the graphics and some of the records that have been distributed for this event are for data that have been low pass filtered to reduce extraneous noise. Some older analyses applied an order 4 Butterworth filter set to $0.5 \mathrm{~Hz}$ (filter LPH). Recent analyses have usually applied a similar filter set to $1.0 \mathrm{~Hz}$ (filter LP1) Gain and characteristics for both filters are shown in Figure 12. Their phase characteristics, shown in Figure 13, indicate that their time lags for low frequency activity are about 0.78 and 0.39 seconds, respectively.

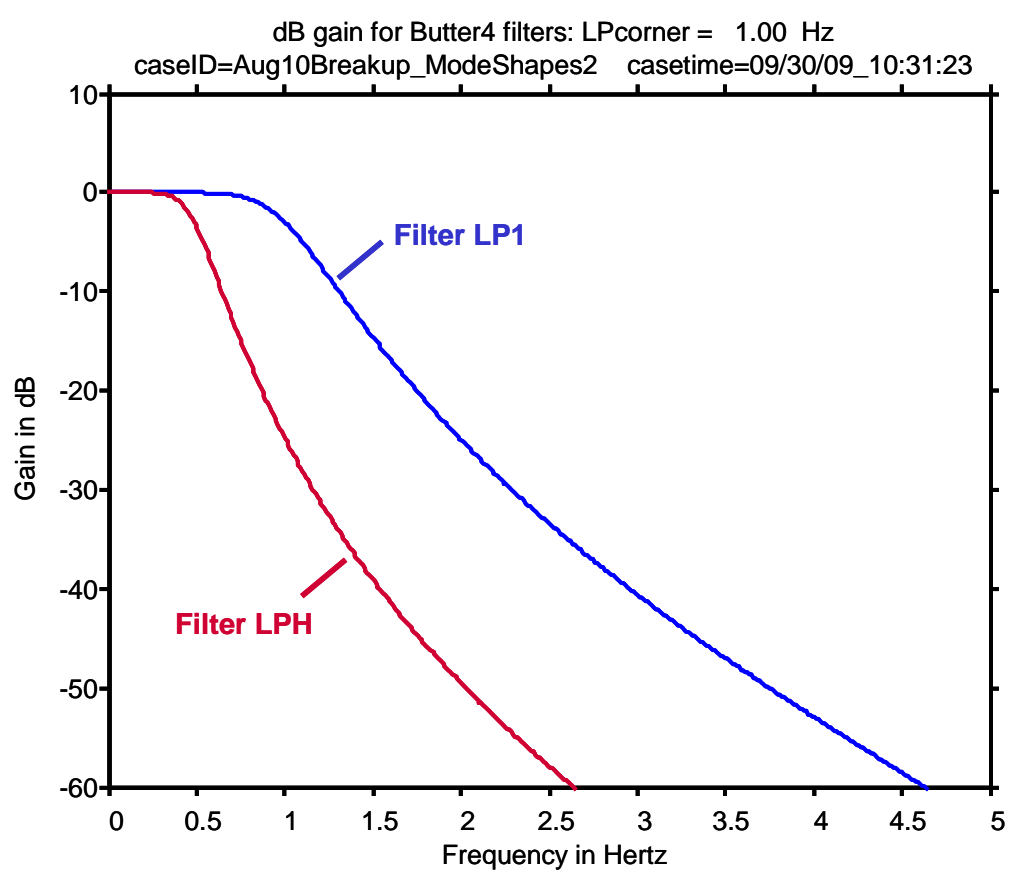

Figure 12. Gain Characteristics for Low Pass Filters LP1 and LPH 


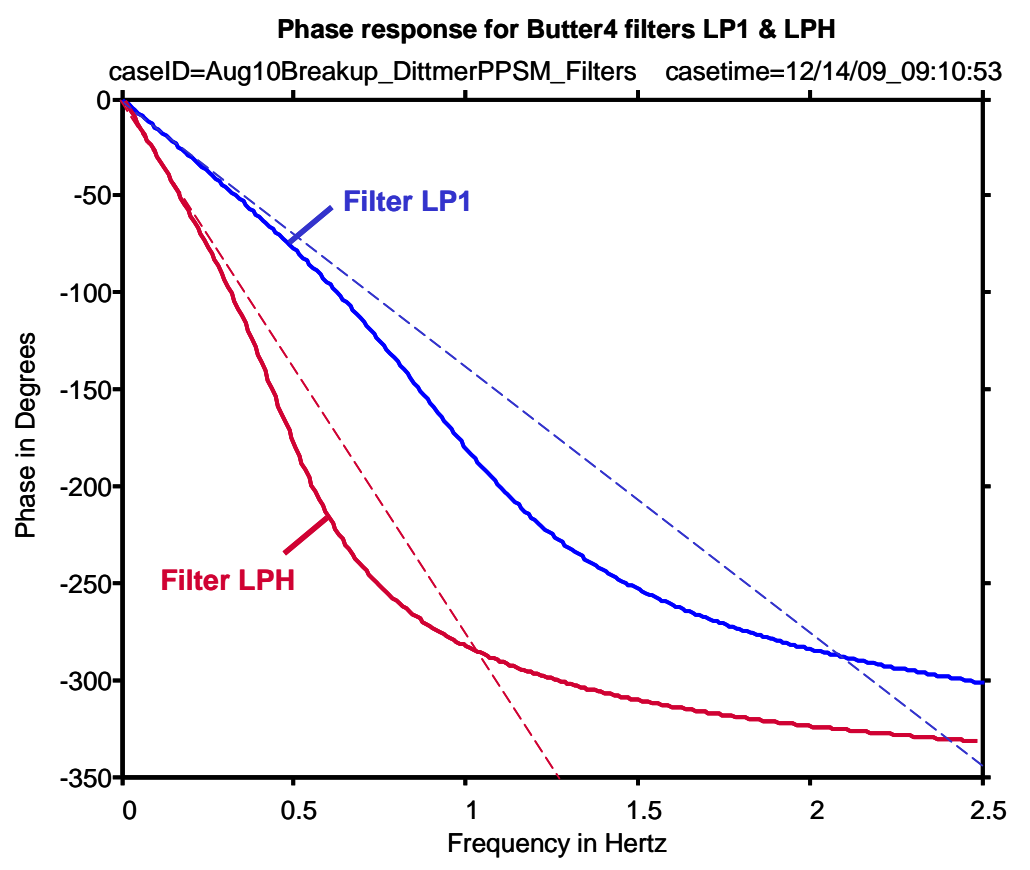

Figure 13. Phase Characteristics for Low Pass Filters LP1 and LPH

Figure 14 and Figure 15 show the effectiveness of LP1 and LPH in revealing the general nature of low frequency activity on the Malin-Round Mountain circuits. In Figure 16, LP1 has been used to smooth oscillatory data in preparation for quantitative analysis [e.g., Prony analysis with the ringdown graphical user interface (GUI)]. Delay of the filtered signal is close to the 0.39 second predicted from Figure 13, and the general shape of the raw signal is well preserved.

Figure 17 through Figure 19 represent a somewhat different situation. Viewed alone, the raw data shown in Figure 17 contains a number of sharp spikes that might be interpreted as indicating control actions on the Pacific DC Intertie (PDCI). However, the broader view in Figure 18 argues that this is unlikely. Similar spikes appear across a much longer time period, and there is no apparent correlation between spikes in different signals. Furthermore, none of the spikes are followed by a significant change in high voltage direct current (HVDC) power level. Overall, the most likely explanation is that most or all of the spikes originated in the measurement system.

When such data are filtered, a brief filter transient will follow each spike. While the transients shown in Figure 19 are minor, close analysis would likely reveal their presence.

Many results, and some data, have been distributed for records that have been bandpass filtered. The most commonly used filter for this is BP1, for which the gain characteristic is shown in Figure 20. Figure 21 shows BP1 applied to the Malin-Round Mountain MW signal of Table 1, and Figure 22 shows the absolute value of the bandpassed signal used as a measure of small signal activity. Low passed versions of the activity signal have been useful in the detection of oscillations and other system events $[13,14]$. The DSI Toolbox provides an "activity filter" for this purpose. 


\section{Aug10Breakup_DittmerPPSM_LPfilters}
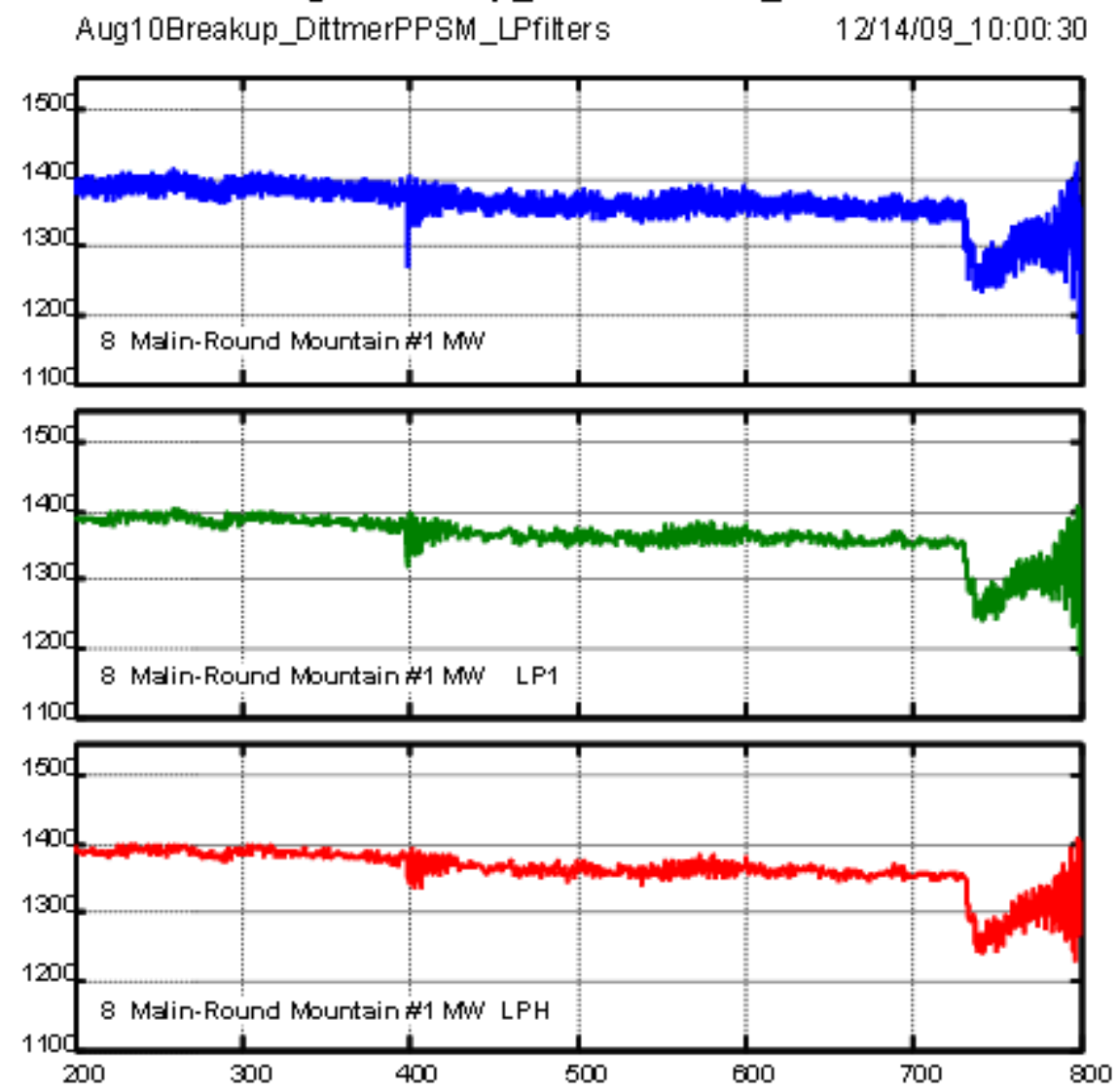

Time in Seconds since 10-Aug-1996 22:35:30.000

Figure 14. Use of LP Filters to Enhance Visibility of Low Frequency Activity in PPSM Records 


\section{Aug10Breakup_Dittm erPPSM_LPfilters}

Aug10日reakup_DittmerPPSM_LPfitters
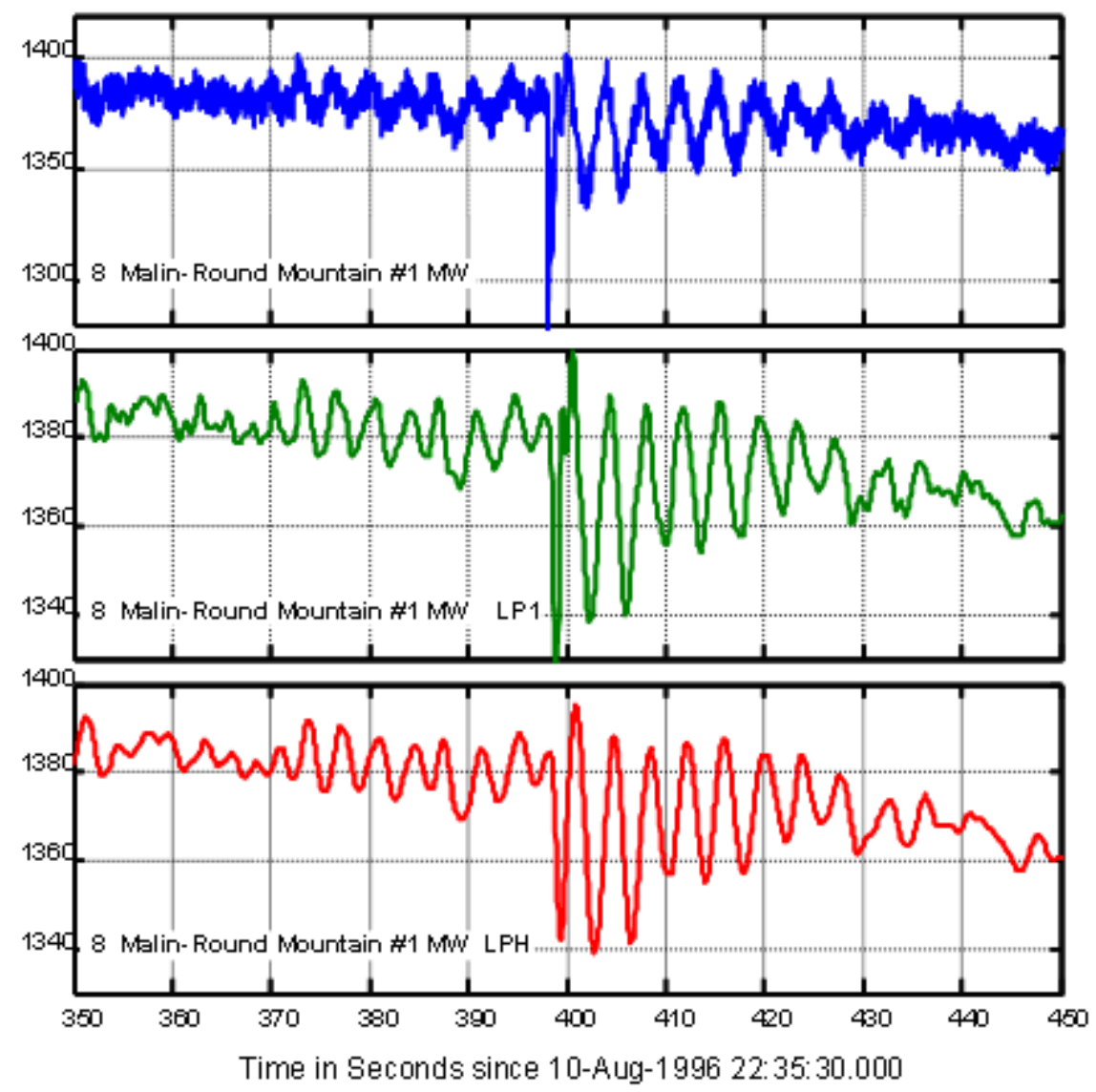

Figure 15. Use of LP Filters to Enhance Visibility of Low Frequency Activity in PPSM Records (detail) ${ }^{4}$

${ }^{4}$ The small oscillations from 372 to 398 seconds remain unexplained. There is a remote possibility it could be single-phase arcing prior to the full fault initiation. The event recorder shows a brief single-phase opening, followed by unsuccessful reclosure and a full line trip beginning at the 398 second mark. 


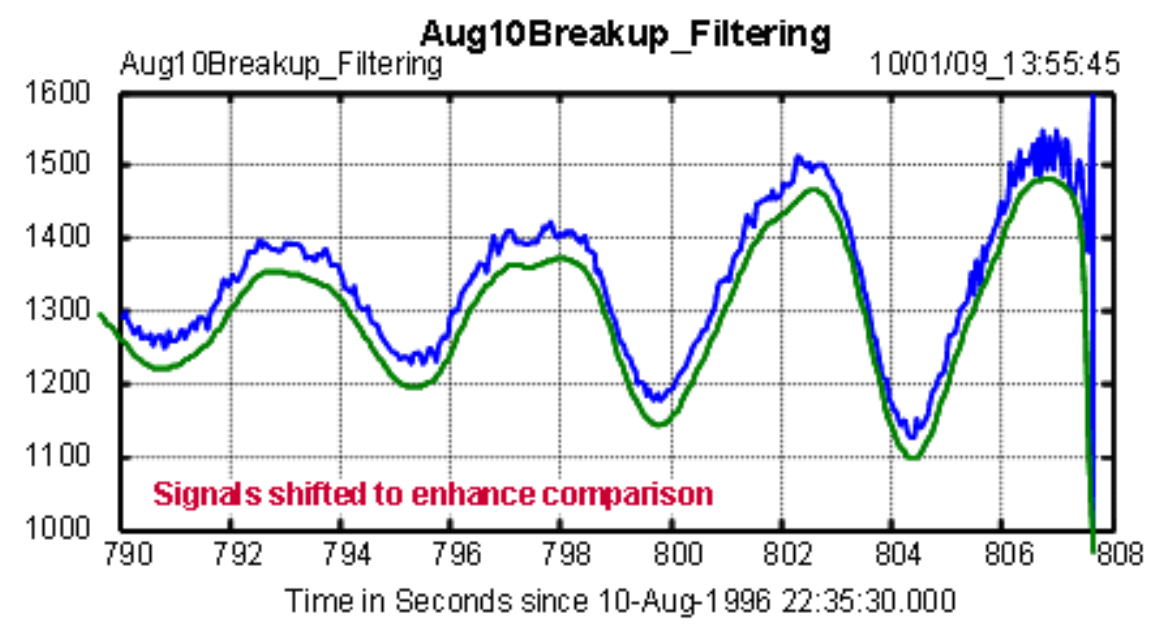

8 Malin-Round Mountain \#1 MW
8 Malin-Round Mountain \#1 MW LP1

Figure 16. Smoothing Effect of LP1 on the PPSM Signal for Malin-Round Mountain \#1 MW

P 3: 30 LACWP Celilo $500 \mathrm{~K} / \mathrm{MW}$

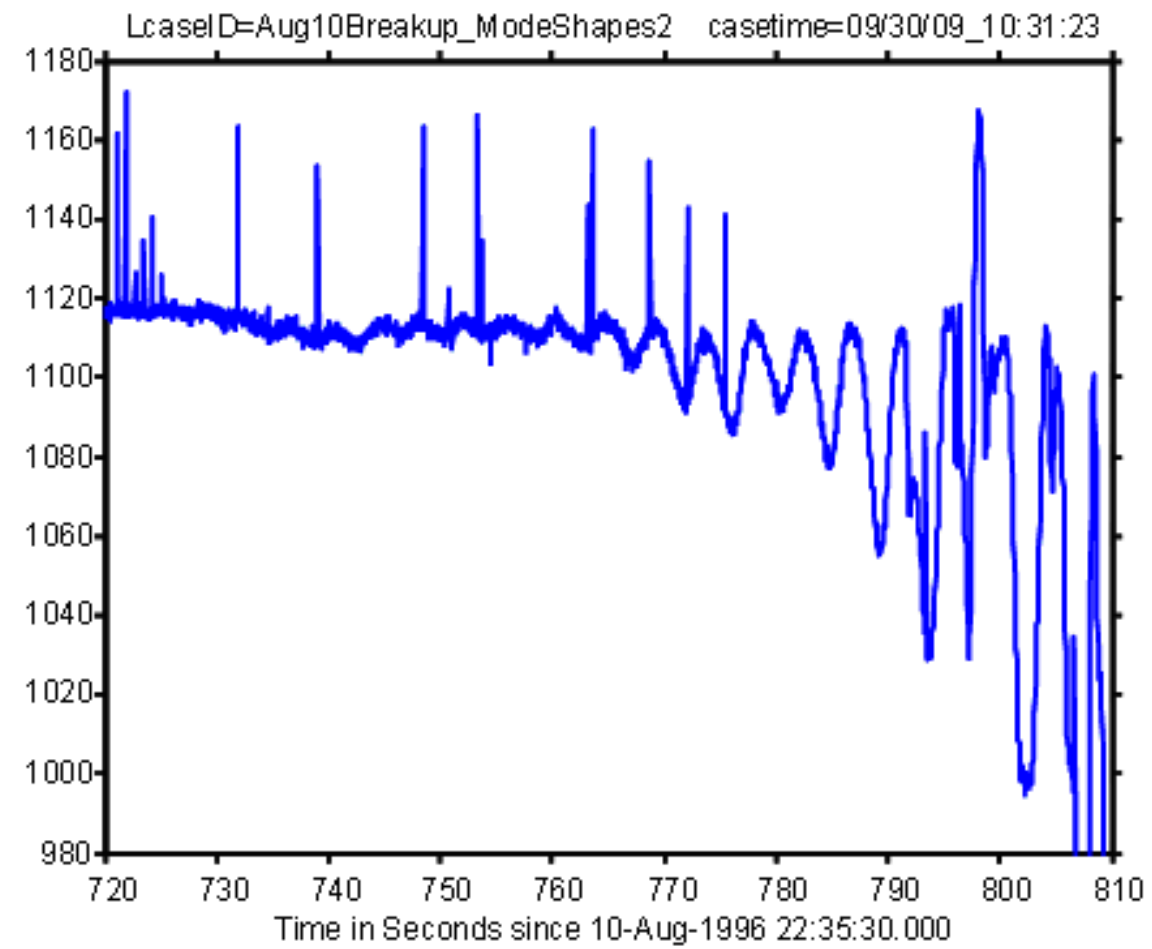

Figure 17. Raw PPSM Data for MW on the Celilo Expansion Converter of the PDCI 


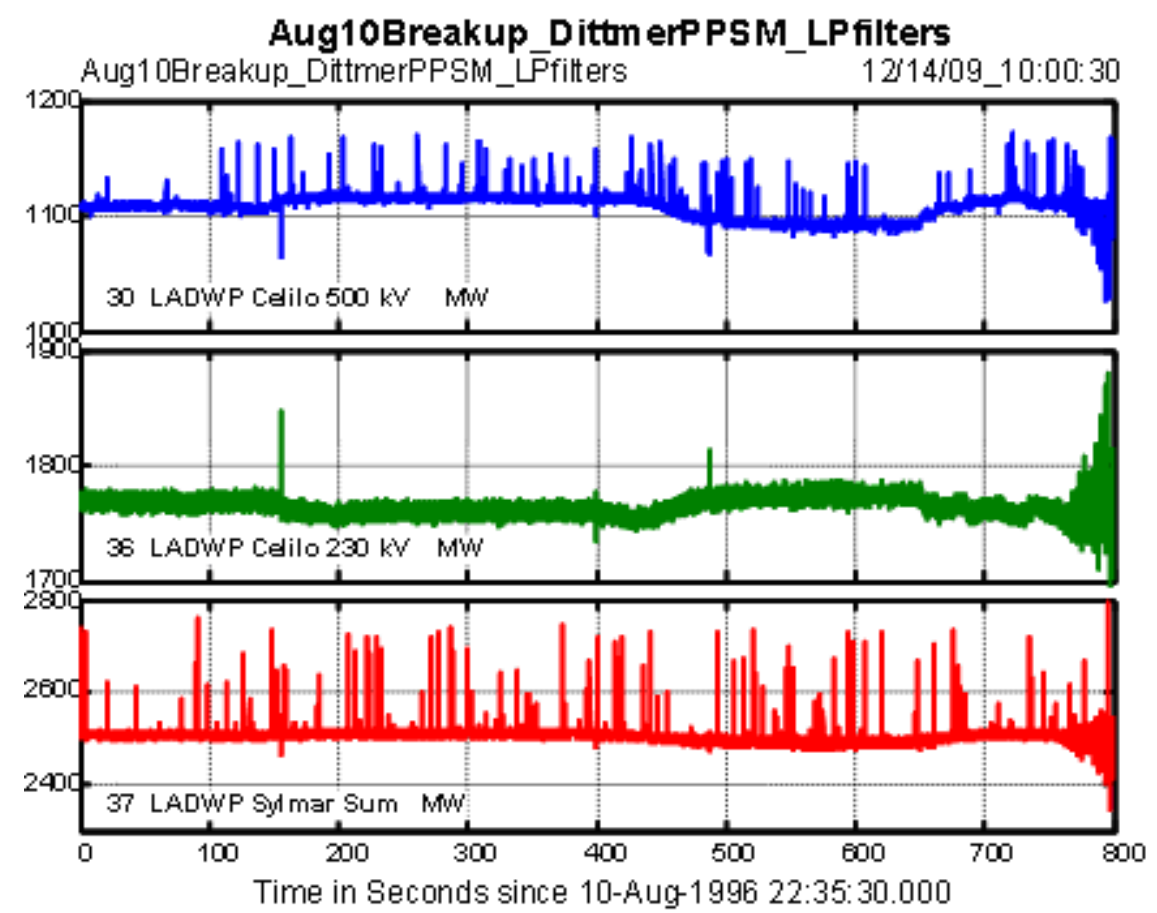

Figure 18. Raw PPSM Data for MW on All Converters of the PDCI

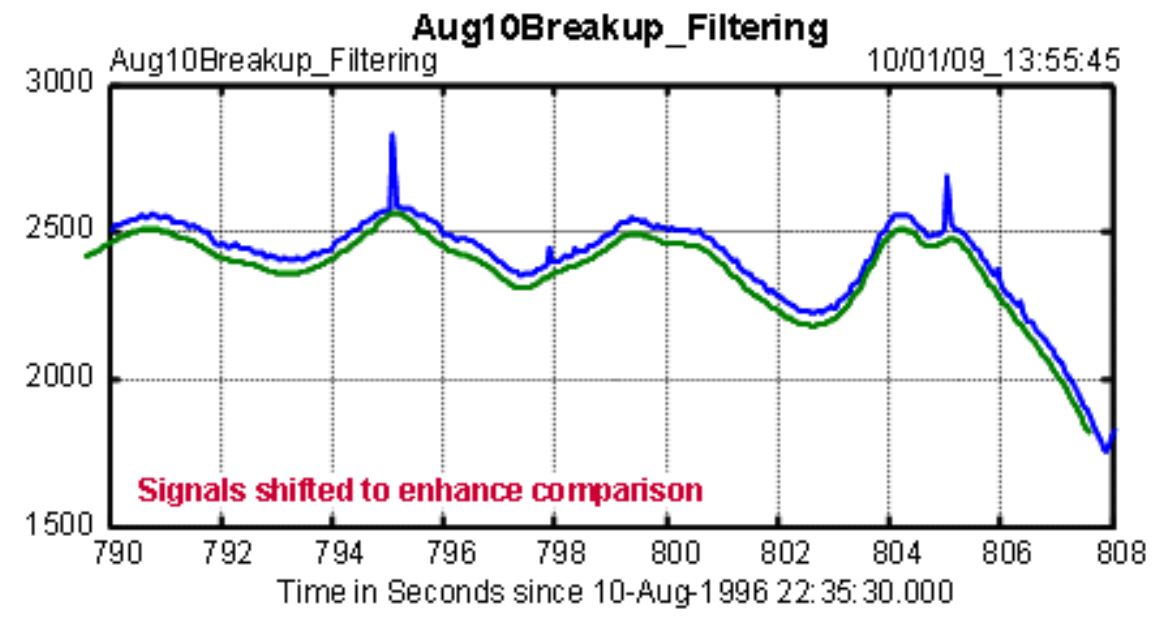

$$
\begin{aligned}
& 37 \text { LADWP Sylmar Sum MW } \\
& 37 \text { LADWP Sylmar Sum MW_LP1 }
\end{aligned}
$$

Figure 19. Effects of LP1 on the PPSM Signal for Total PDCI MW at Sylmar 


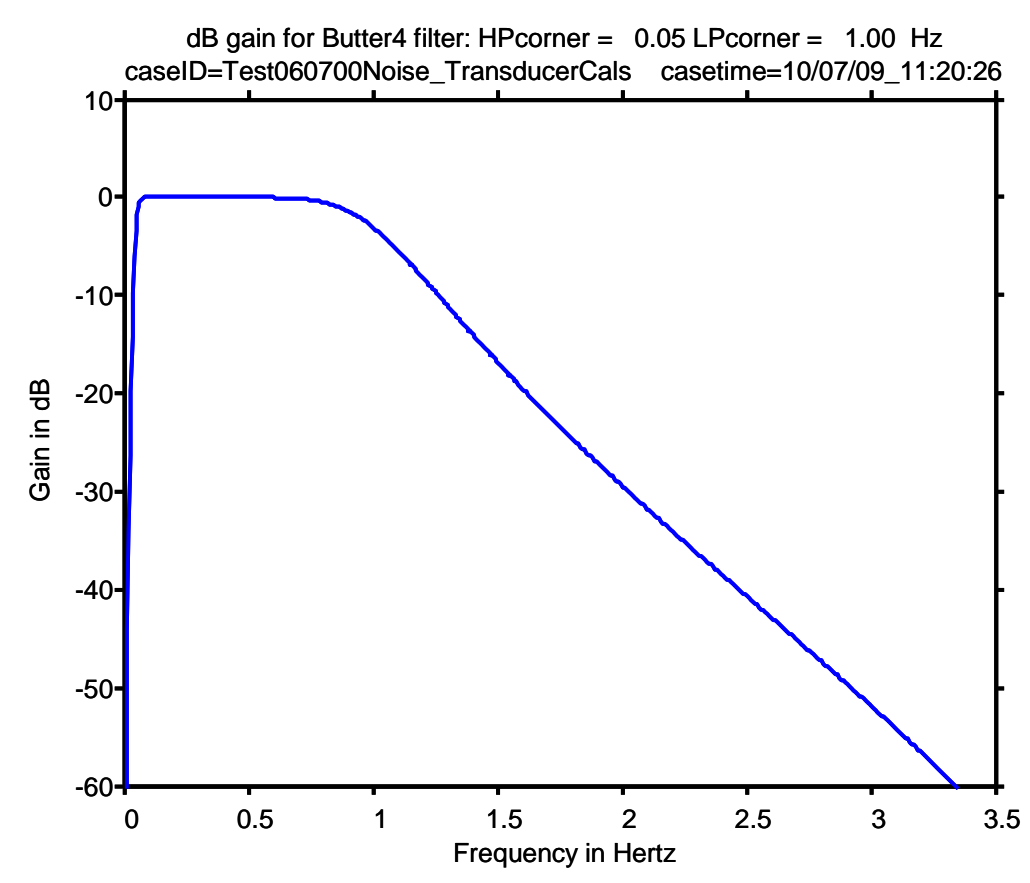

Figure 20. Gain Characteristic for Bandpass Filter BP1

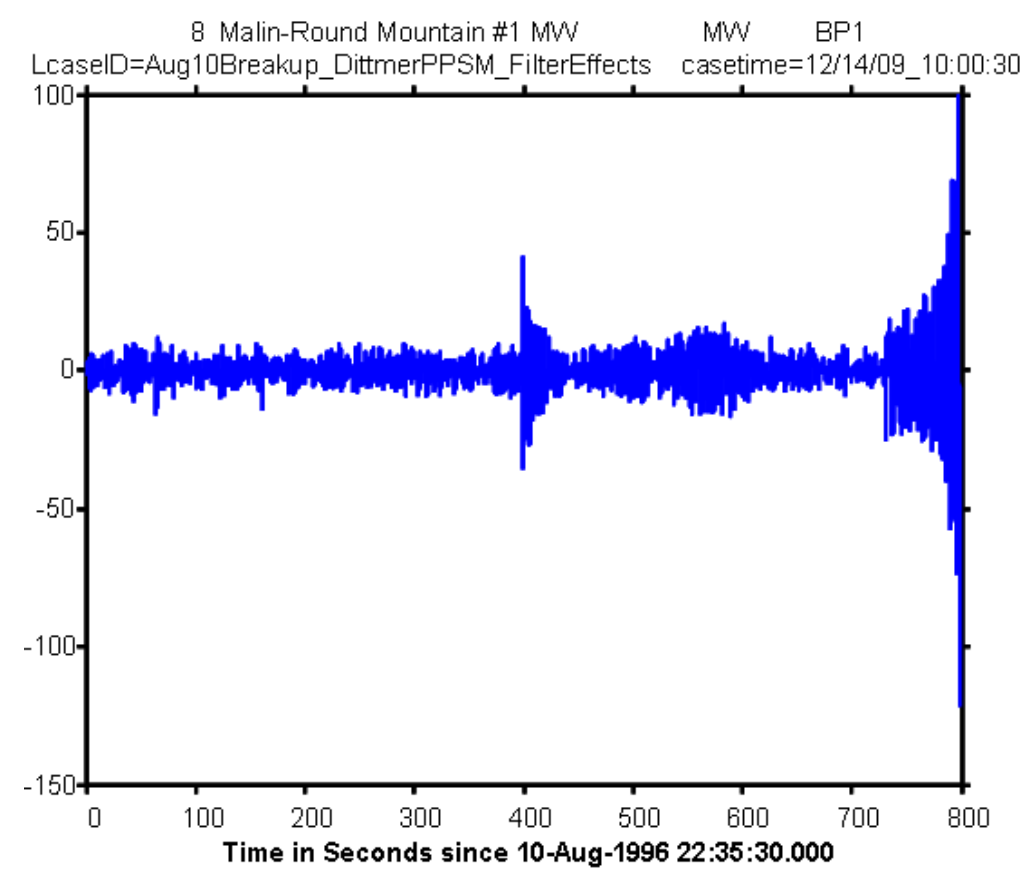

Figure 21. Use of Bandpass Filter to Enhance Visibility of Small Signal Activity in PPSM Records 


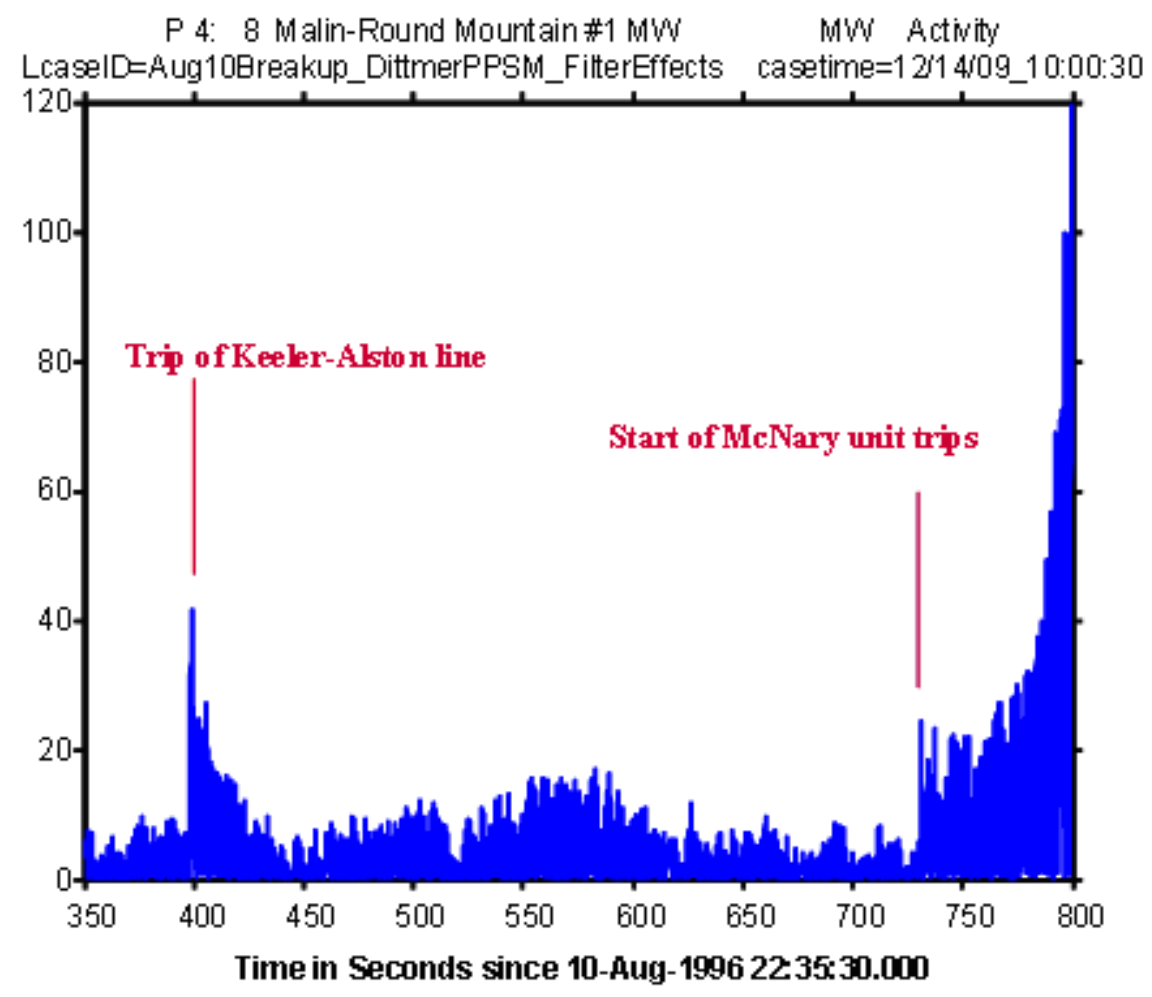

Figure 22. Use of Absolute Value of Bandpassed Signal to Measure Activity

\section{Transducer Effects}

Processing differences among transducers of different types can result in highly inconsistent views of power system events. A strong example of this is shown in Figure 23, for transducers that were in service at Malin for the August 10 breakup. All of these transducers were responding to equal inputs. MW signals from the PMU and the enhanced analog transducer track very closely, but signals from the standard analog transducers lag by roughly one half-second.

Data for the August 10 breakup was collected on a wide variety of transducer types, and each type colored the apparent timing of its output signals in a different manner. These effects can be corrected by "defiltering" if a model for the transducer processing is available. Short of this, analysis results for analog transducers can be adjusted by comparing their outputs against those of PMUs that meter the same signals.

A good opportunity to cross-calibrate analog transducers against their PMU counterparts was provided by a staged WSCC system test on June 7, 2000 [15]. Two different approaches to this are demonstrated in the materials to follow. The first is to cross-correlate the transducer outputs through Fourier analysis, and the other is to examine their relative timing through Prony analysis. 

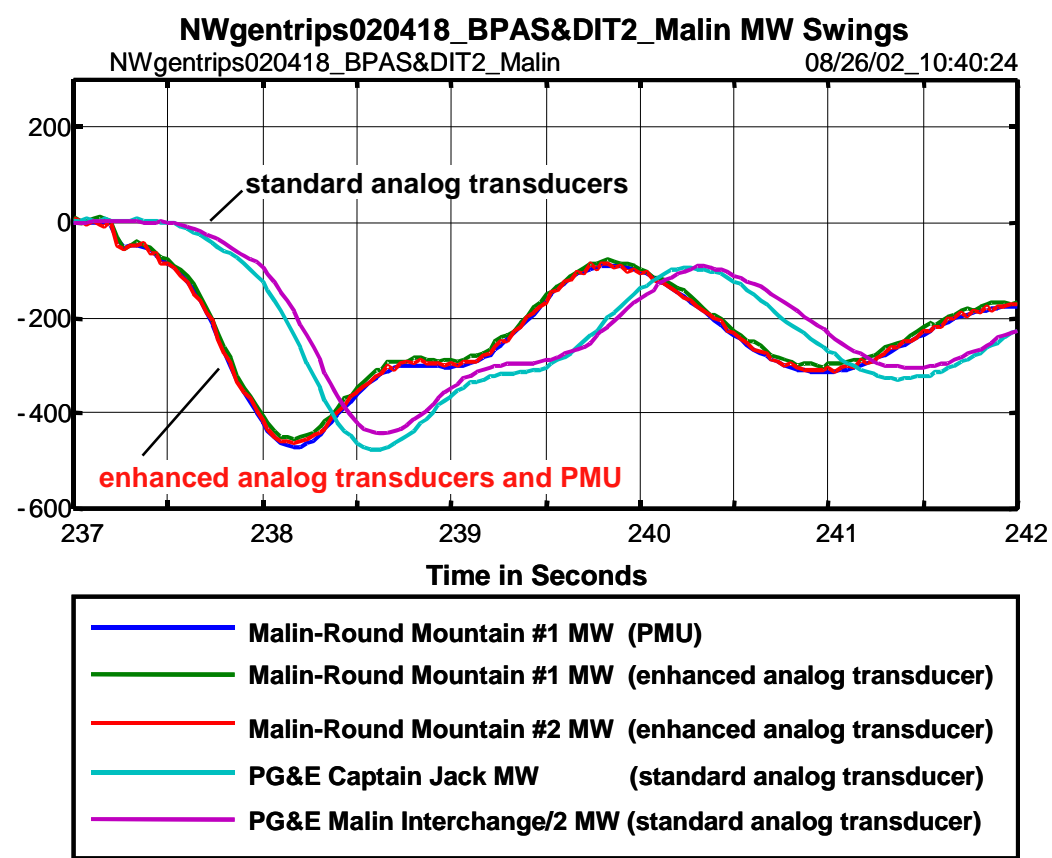

Figure 23. Inconsistent Signals for NW Generation Trip Event on April 18, 2002 (initial offsets removed)

A basic Fourier method for cross-calibrating different transducers is shown in Figure 24 and Figure 25. The data were collected for noise probing during the tests on June 7, 2000. Figure 24 shows that signals from the PPSM and the PMU have almost precisely the same frequency content, and that the bandwidth of the PMU output signal rolls of somewhat faster than that of the PPSM signal. Coherency of the two signals is very high below $0.4 \mathrm{~Hz}$. Measurement noise becomes stronger above that frequency, and the coherency curve becomes more irregular. Figure 25 shows the apparent response of the PPSM signal to the PMU signal. The gain is close to unity out to $0.4 \mathrm{~Hz}$, and the relative phase is close to zero. Consistent with later Figure 32, this argues that time alignment of the PPSM and the PMU records is very close.

Figure 26 and Figure 27 show a similar comparison of transducer signals for the 230-KV converter of the PDCI. Frequency contents are consistent, and coherency is high. However, the relative frequency trace in Figure 27 has a strong downward ramp, which indicates a relative lag of approximately 0.395 second for the analog transducer signal recorded on the PPSM. Figure 28 and Figure 29 show similar results for the 500-KV converter, but with an estimated delay of 0.242 second.

The three PMUs shown in Figure 24 through Figure 29 seem to be the only ones that share inputs with the analog transducers of August 10, 1996 and were in service for the June 2000 tests. Additional PMUs that share such signals may have been installed since then, but cross-calibration against their outputs has not been attempted as yet. 
Malin-Round Mountain \#1 MW PPSM_BP1//MALN Round Mountain 1 Current MW PMU_BP1

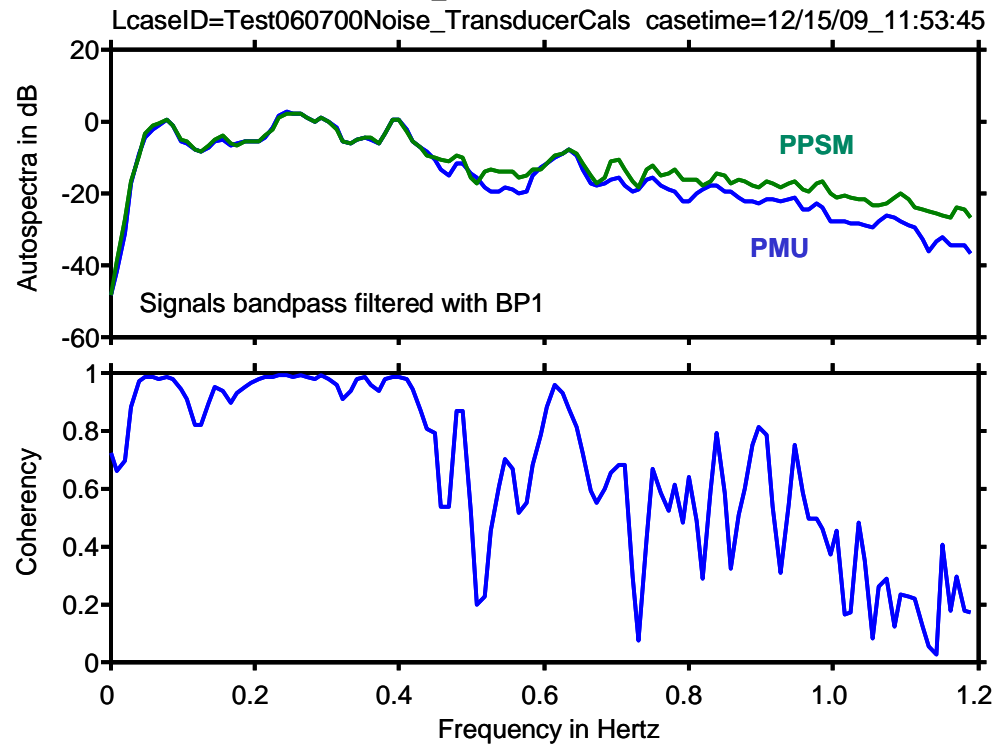

Figure 24. Spectra and Coherency of PPSM Signal Relative to PMU Signal Malin-Round Mountain \#1 MW, Filtered with BP1

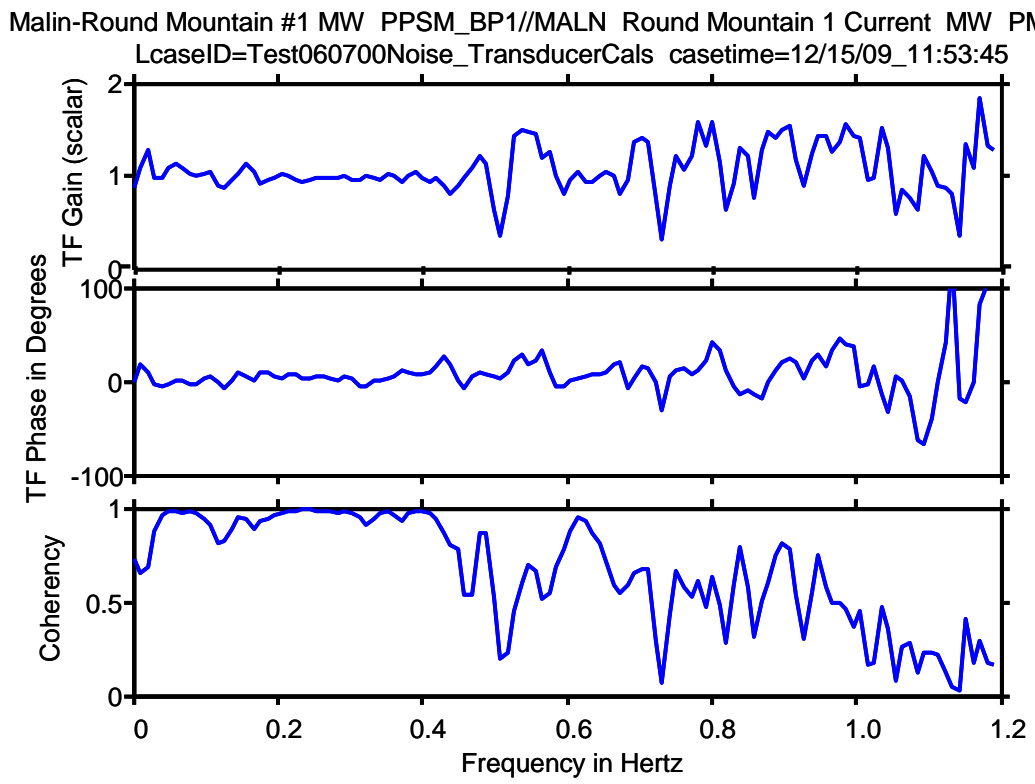

Figure 25. Virtual Frequency Response of PPSM Signal to PMU Signal Malin-Round Mountain \#1 MW, Filtered with BP1 


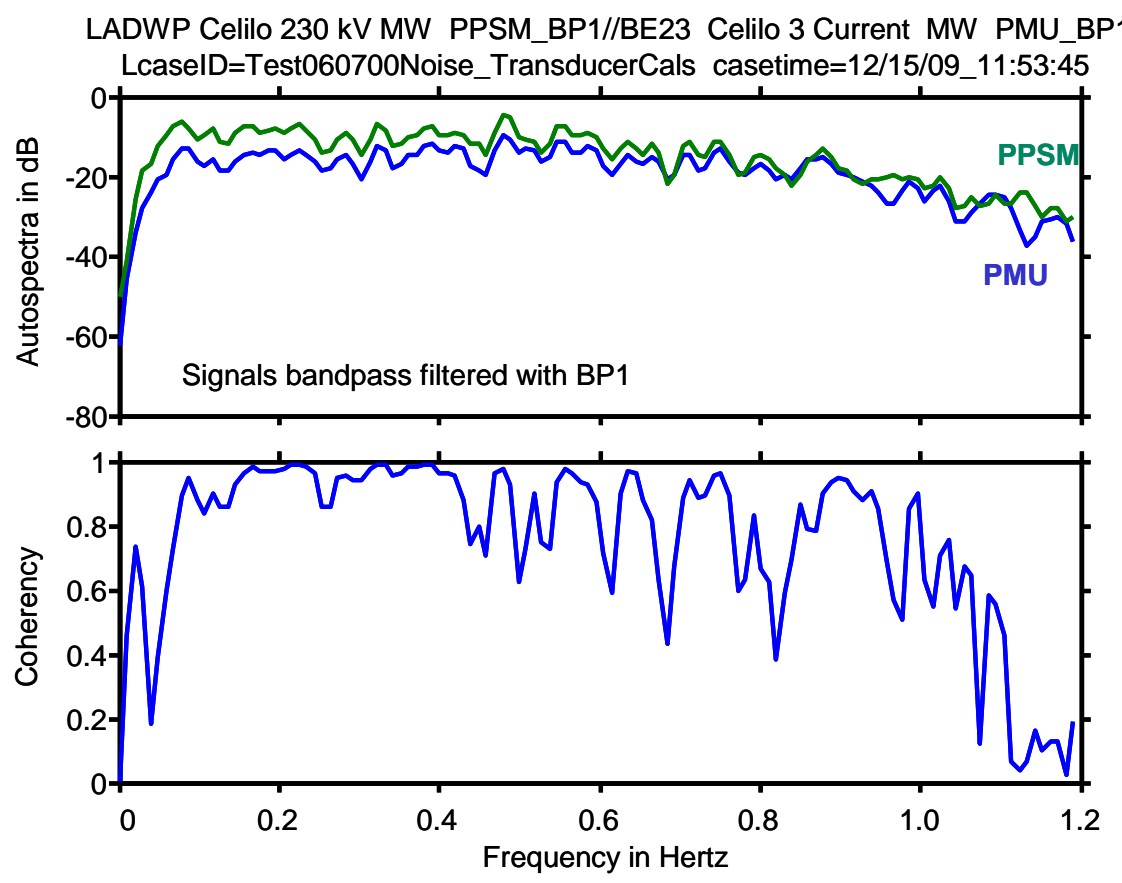

Figure 26. Spectra and Coherency of PPSM Signal Relative to PMU Signal Celilo 230 KV MW, Filtered with BP1

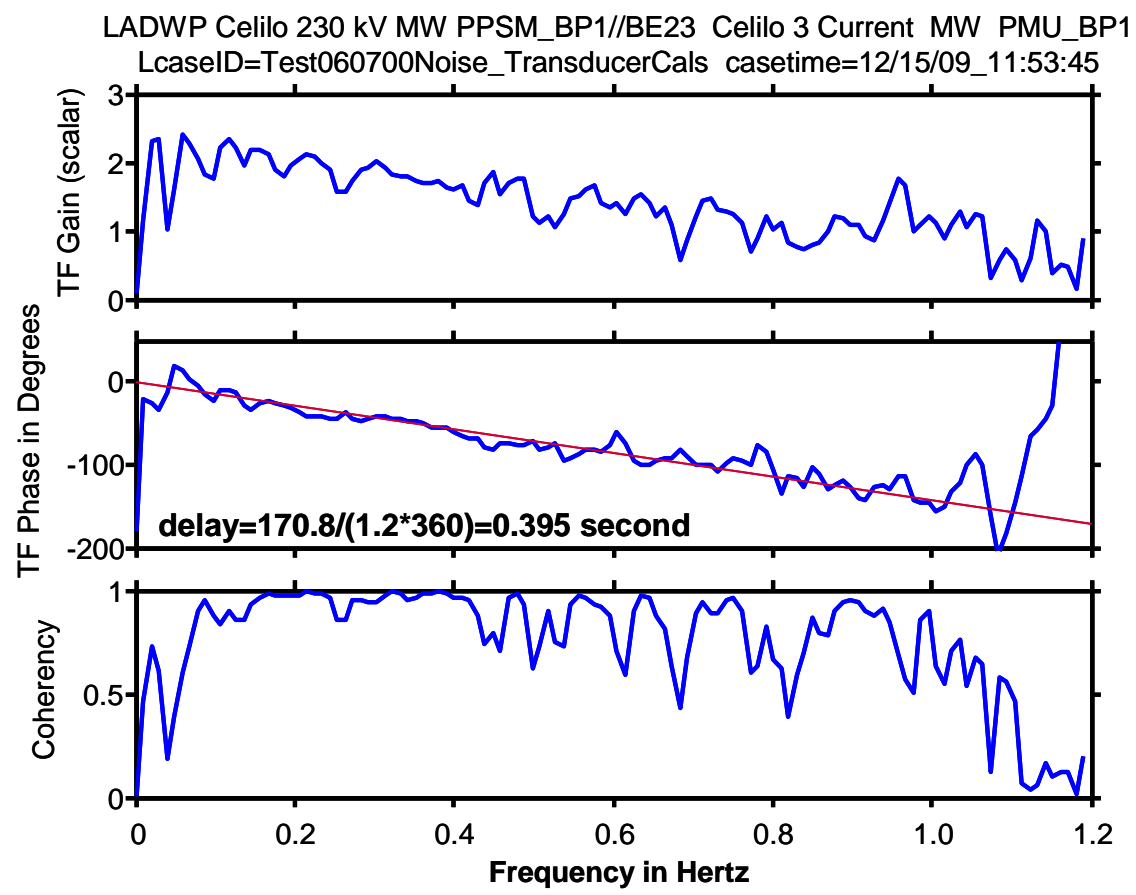

Figure 27. Virtual Frequency Response of PPSM Signal to PMU Signal Celilo 230 KV MW, Filtered with BP1 

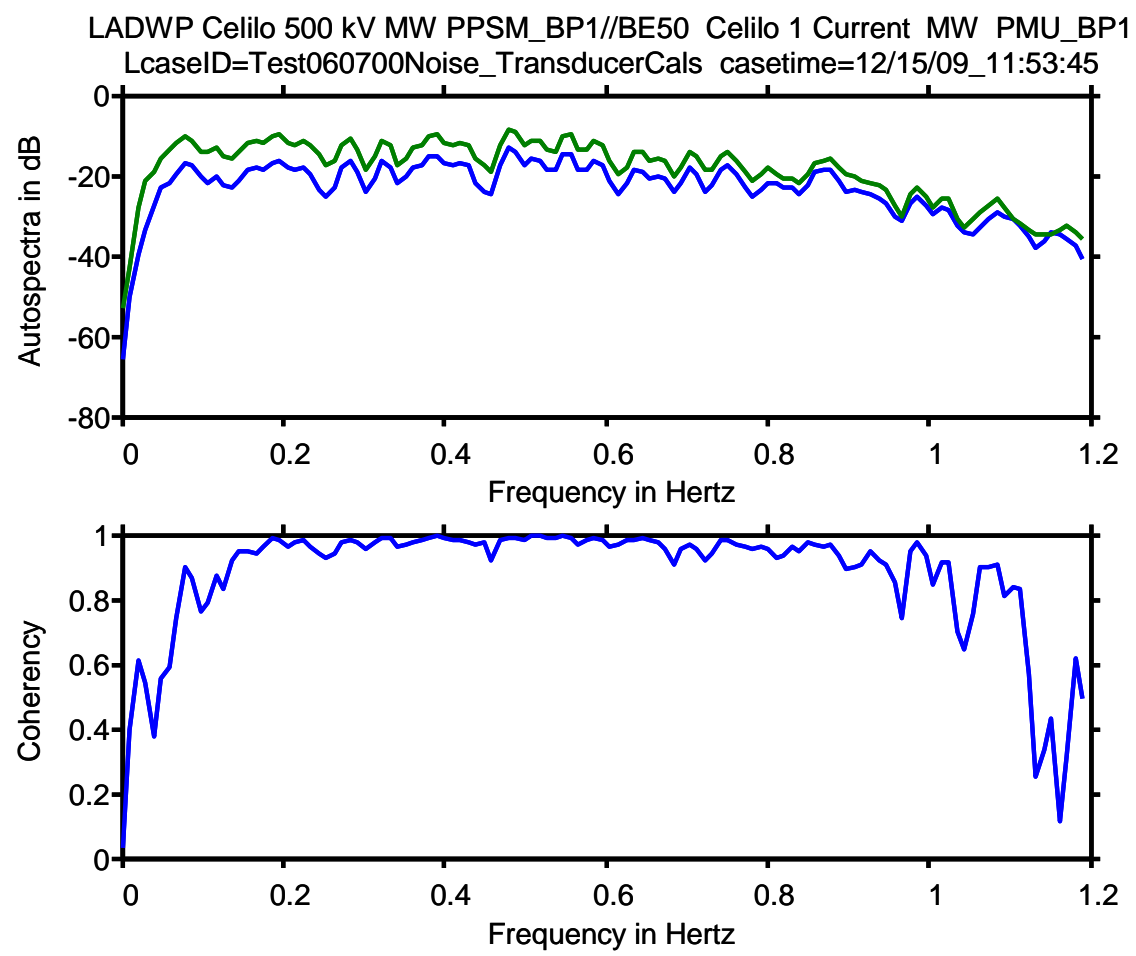

Figure 28. Spectra and Coherency of PPSM Signal Relative to PMU Signal Celilo 500 KV MW, Filtered with BP1

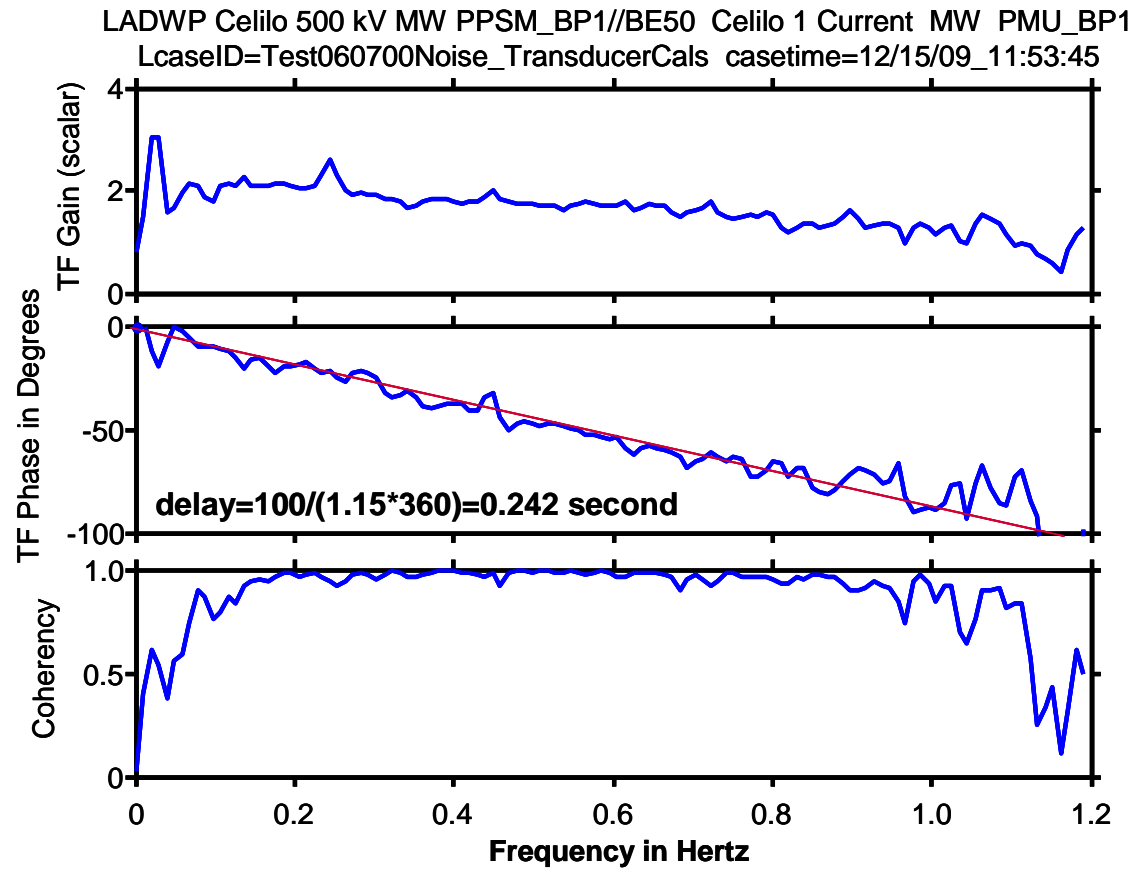

Figure 29. Virtual Frequency Response of PPSM Signal to PMU Signal Celilo 500 KV MW, Filtered with BP1 
The June 7 tests also produced another kind of response data that is more convenient for transducer calibrations. In this case the probing signal was a brief square wave, as shown in figure 30 . The figure also compares the resulting waveforms from primary transducers associated with the PDCI. The analog transducer signals recorded on the PPSM are conspicuously sluggish, and by different amounts. The PMU signals, on the other hand, are well synchronized, and their waveforms are all very similar. A simpler view of equivalent measurements produced by the two technologies is provided in Figure 31.

Figure 32 indicates good time alignment of the PPSM records against PMU records from the BPA phasor data concentrator (PDC). The PPSM records were 20 seconds late, however, and the time stamp was decreased by this amount to achieve the correct alignment.

Figure 33 and Table 2 shows relative timing as determined by Prony analysis for the applied $0.3-\mathrm{Hz}$ train of probing pulses. The relative phase angles indicate that the analog signals have been delayed by 0.4423 second and 0.2743 second for the $230-\mathrm{KV}$ and the $500-\mathrm{KV}$ line MW signals, respectively. This compares fairly well with the 0.395 second and 0.242 second estimates obtained above with Fourier methods. Relative delay is also estimated for a delayed image of the test pulse. The estimated value of 0.3975 second compares well against the actual 0.4 second built into the data.
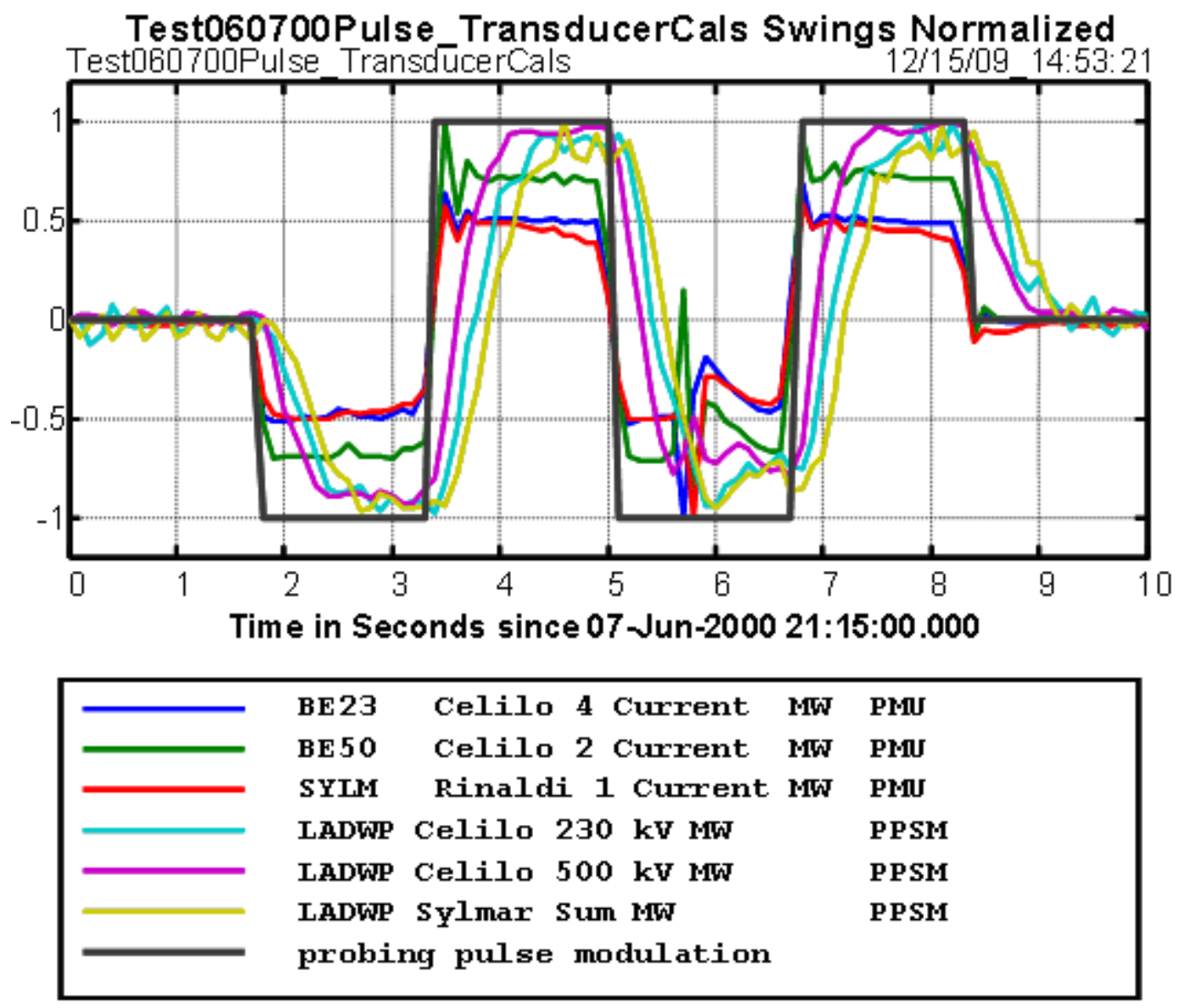

Figure 30. PDCI Transducer Responses to Single-Mode Probing on June 7, 2000 

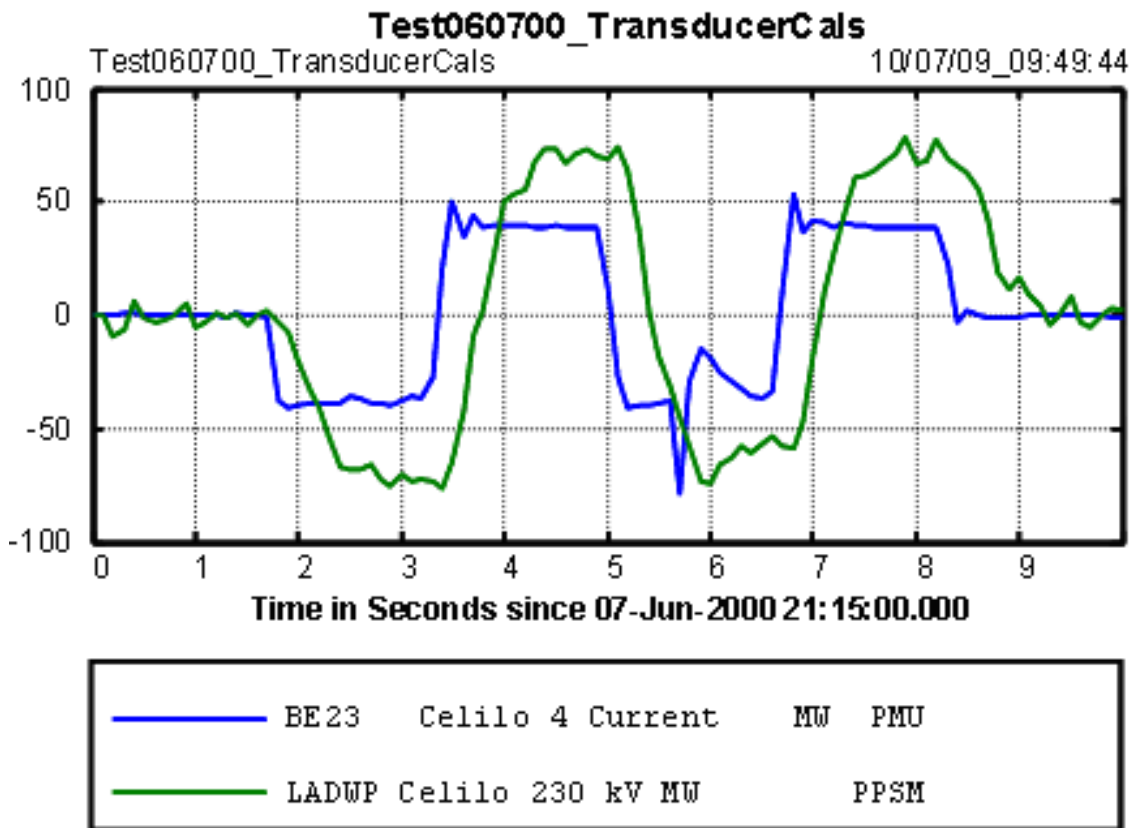

Figure 31. PDCI Transducer Responses to Single-Mode Probing on June 7, 2000 (detail)

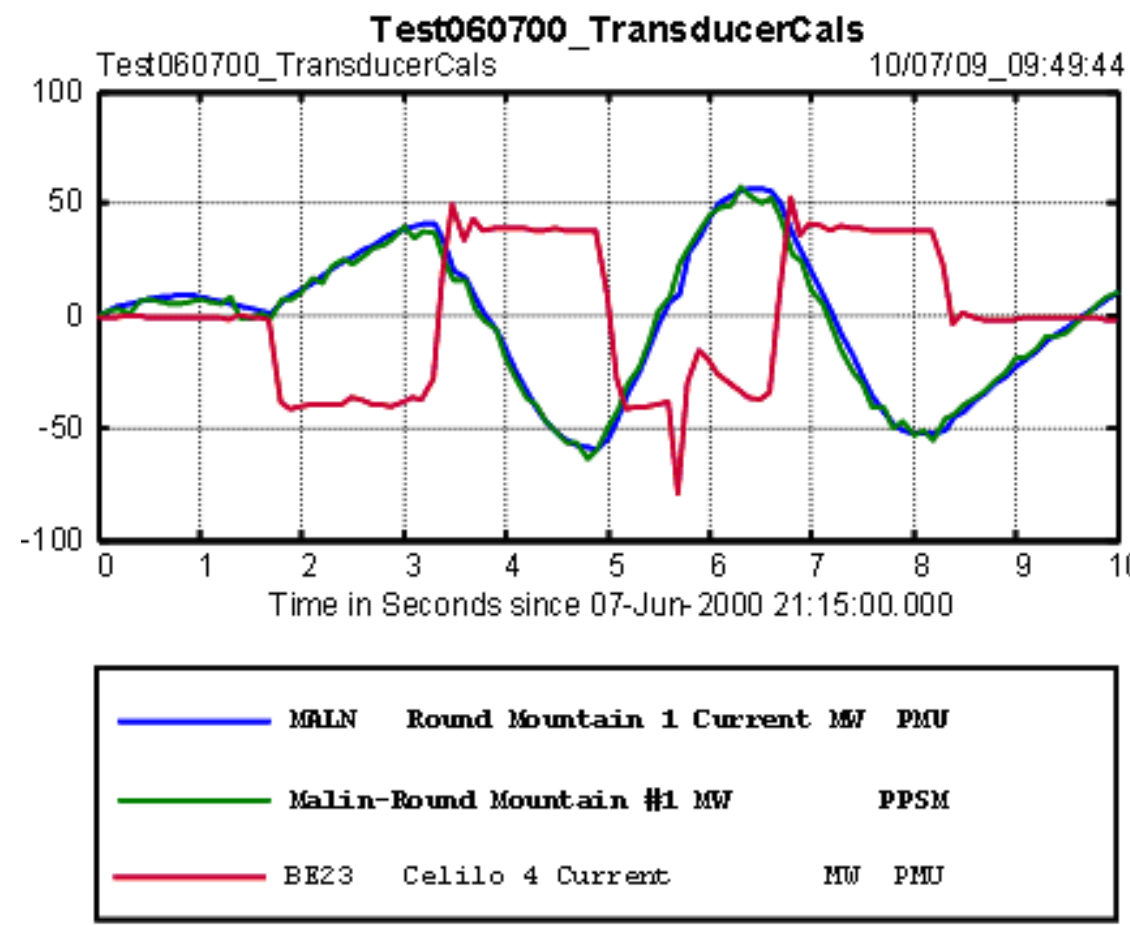

Figure 32. Validation of PPSM Timing vs. PMU

(PPSM time stamp advanced 20 seconds) 


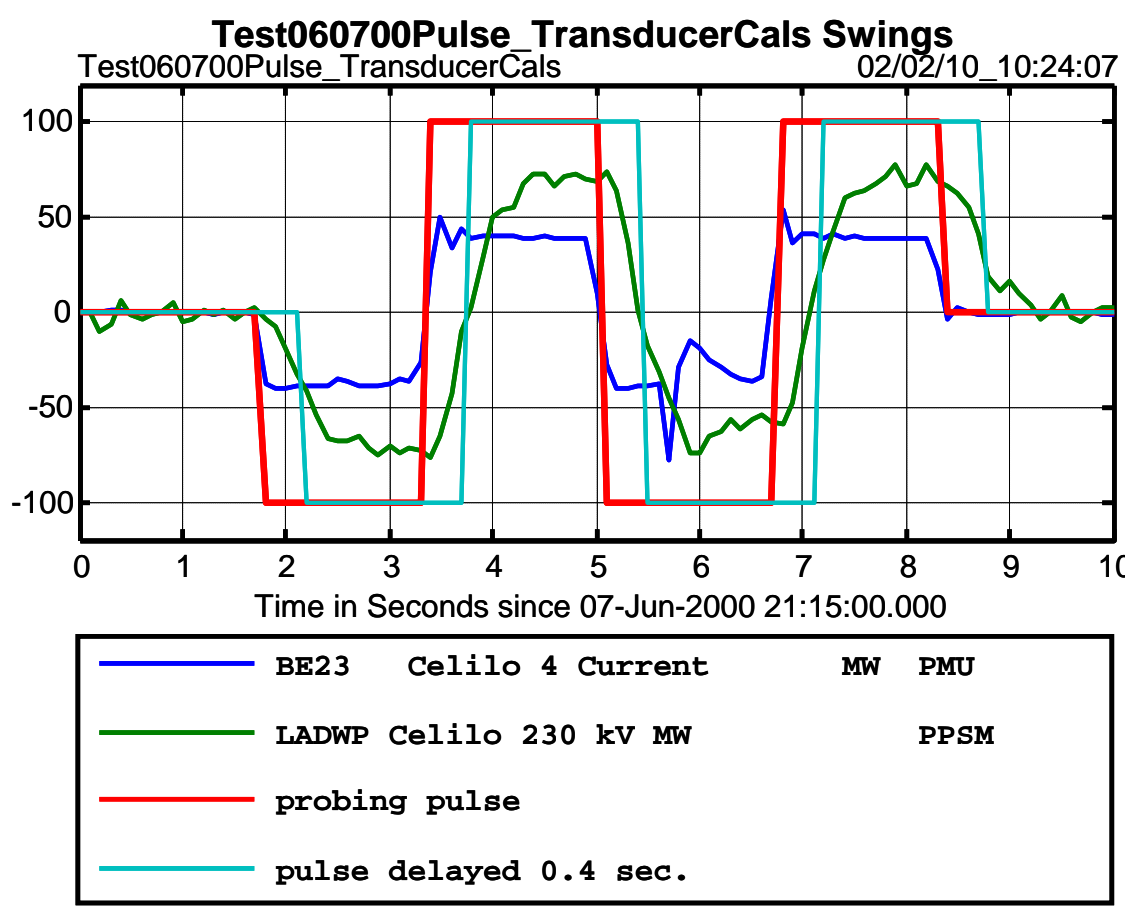

Figure 33. Validation of PPSM timing vs. PMU (detail) (PPSM time stamp advanced 20 seconds)

Table 2. Prony Results for 0.3 Hz Probing Pulse (Trange=[1.7 8.4] seconds, except [2.1 8.8] for delayed pulse)

Signal

BE23 Celilo 4 Current MW PMU

BE50 Celilo 2 Current MW PMU

LADWP Celilo 230 kV MW PPSM

LADWP Celilo 500 kV MW PPSM

Probing pulse

Pulse delayed 0.4 second
Residue Angle

$-86.08198219$

$-89.80137523$

$-133.85374719$

$-119.42047465$

$-91.64057541$

$-134.56671272$

\section{Relative Delay}

0.0

0.0

0.4423

0.2743

0.0

0.3975

\section{Prony Analysis}

Prony analysis results in Kosterev et al. [3] differ somewhat from those in Hauer 1997 [4] and in Table H1 of Hauer's commentary [3]. This is partly attributable to use of slightly different analysis windows. However, it appears from [2,5] that the Prony software used for the BPA analysis was an older PSAPAC version that processed one signal at a time, rather than multiple signals in tandem (as in the PNNL version). None of these documents provides full processing details, so their results may be difficult to replicate exactly. It is, of course, quite possible that results from contemporary software would be superior. 
A fundamental assumption in Prony analysis is that the data under analysis corresponds to time windows for which the dynamic system is free of topology changes or exogenous inputs. Figure 34 below shows numerous generator trips at the McNary plant during the final oscillation stage, with fairly brief intervals between them. Correct results require that the analysis windows be confined to these intervals, or at least not extend too far beyond them. Applying a broad analysis window to the seemingly smooth oscillations in Figure 35 would require some other kind of tool.

Aug10Breakup_Dittm erPP SMraw Swings

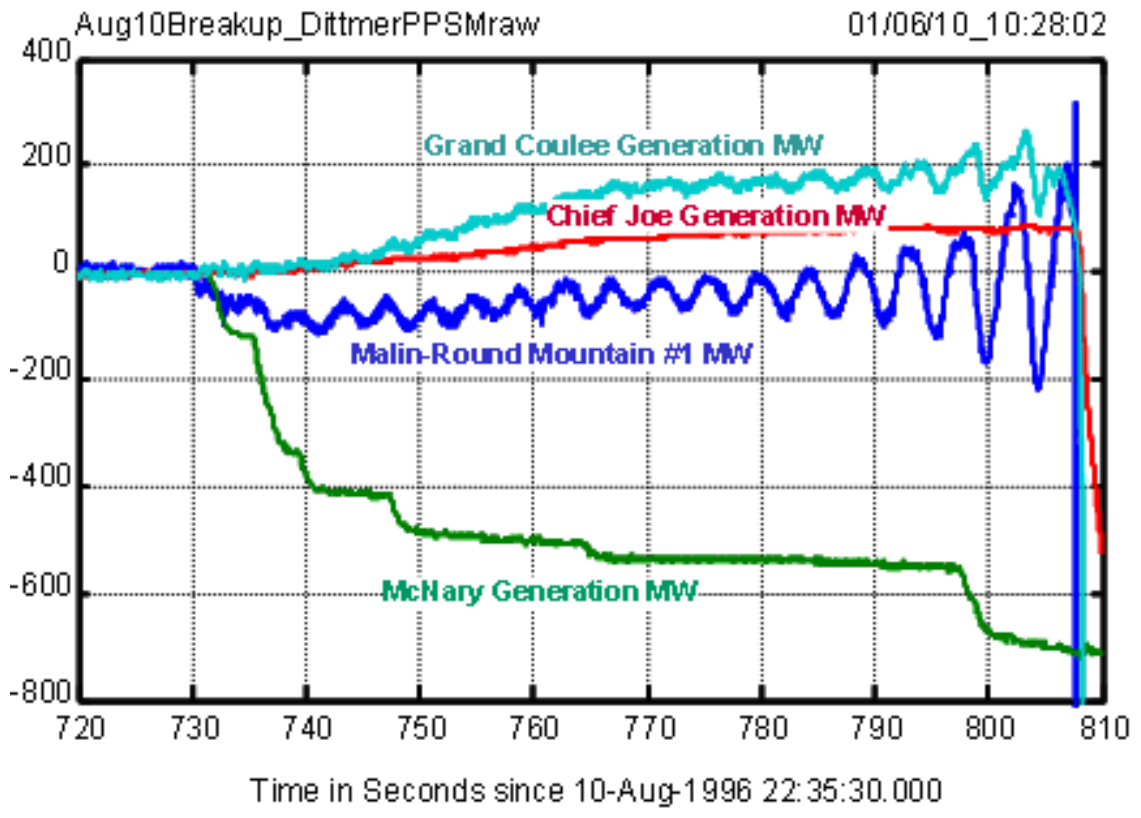

Figure 34. McNary Unit Trips during Final Oscillations 

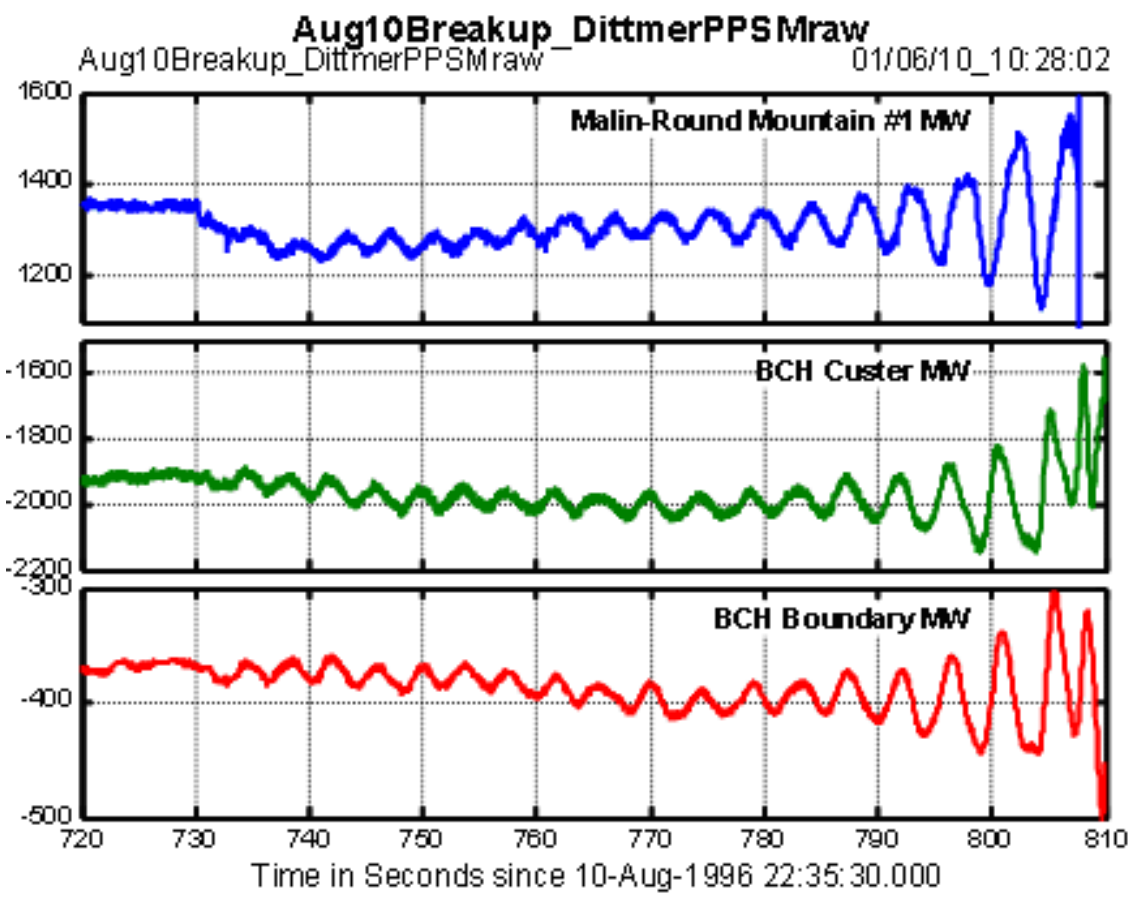

Figure 35. Final Oscillations on Interchanges with Canada 


\section{Conclusions}

The immediate intent of this report is to preserve recorded data from the August 10, 1996 breakup event and to provide additional information that is important to the correct interpretation and use of these data. Copies of the data can be obtained from the Bonneville Power Administration (BPA), or from PNNL with BPA concurrence.

Although specific to the breakup of August 10, 1996, this report demonstrates some general issues concerning the use of archived measurements. Some raw data sets require repair before they are even usable [16], and some kinds of analysis require data enhancements. It is important that both processes be performed in a standard manner, and that each data set be accompanied by a processing log that clearly indicates the origins and history of the data.

The DSI Toolbox maintains this processing log automatically, in a text file called CaseComR [9]. Under some conditions signal names are modified to indicate special processing or context - e.g, a postfix like _BP1 may be added to indicate filtering with a filter that the user has designated as BP1. These features were not fully evolved in very old versions of the DSI Toolbox, however, and it is not uncommon for a data user to periodically empty the processing log as a matter of temporary convenience. In such cases, the data user is well advised to determine the data history before conducting a major analysis. 


\section{References}

WECC work group documents cited here are available at ftp.bpa.gov/pub/WAMS\%20Information/, or by special request to the authors.

[1] Western Systems Coordinating Council Disturbance Report for the Power System Outage that Occurred on the Western Interconnection August 10, 19961548 PAST. Approved by the WSCC Operations Committee on October 18, 1996. Available on the Internet at http://www.wscc.com/outages.htm.

[2] Review of Selected 1996 Electric System Disturbances in North America. Report of the North American Electric Reliability Council (NERC), August 2002.

[3] Kosterev, D.N., C.W. Taylor and W.A. Mittelstadt. 1999. "Model validation for the August 10, 1996 WSCC system outage.” IEEE Trans. Power Systems, vol. 14, no. 3, pp. 967-979, Aug. 1999.

[4] Hauer, J. 1997. Oscillation History for the WSCC Breakup of August 10, 1996. WAMS Working Note, January 28, 1997. (extended April 4, 2000)

[5] Morrison, K., et al. 1997. System Disturbance Stability Studies for Western System Coordinating Council (WSCC), K. Morrison and others. EPRI Report TR-108256, prepared by Powertech Labs Inc., September 1997.

[6] Hauer, J. 2001. Use of Synchronized Phasor Measurements to Correct Timestamp and Filter Effects in Monitor Records Collected from Analog Instrumentation: Applied to Records of June 7, 2000 and August 10, 1996, J. F. Hauer. Working Note for the WECC Modeling \& Validation Work Group, December 20, 2001

[7] Hauer, J., and J.R. Hunt, in association with the WSCC System Oscillations Work Groups. 1996. "Extending the Realism of Planning Models for the Western North America Power System," V Symposium of Specialists in Electric Operational and Expansion Planning (SEPOPE), Recife (PE) Brazil, May 19-24, 1996.

[8] Hauer, J.F., D.J. Trudnowski, G.J. Rogers, W.A. Mittelstadt, W.H. Litzenberger, and J.M. Johnson. 1997. "Keeping an Eye on Power System Dynamics," IEEE Computer Applications in Power, pp. 50-54, October 1997.

[9] Hauer, J.F. and J.M. Johnson. 2001. A User Guide to PSM Tools: Utilities for Matlab Processing of Power System Response Records. Prepared for the U.S. Department of Energy Transmission Reliability Program by the Consortium for Electric Reliability Solutions (CERTS), February 2001.

[10] Trudnowski, D.J., J.F. Hauer, and G.J. Rogers. 1998. DSItools Application Guide for the Power System Modal Analysis, Pacific Northwest National Laboratory, 1998.

[11] Guttromson, R.T., J. M. Johnson and J.F. Hauer. 2001. A Utility for Writing Dynamic Simulation Data into Swing Export Files for External Processing, Working Note for the WSCC Modeling \& Validation Work Group, April 6, 2001. 
[12] Hauer, J.F. 2002. Integrated Records and Graphics for PMU Data Collected during the WSCC Breakup of August 10, 1996. Working Note for the WECC Modeling \& Validation Work Group, January 14, 2002.

[13] Hauer, J.F., and F. Vakili. 1990. "An Oscillation Trigger Used in the BPA Power System Disturbance Monitor." IEEE Trans. Power Systems, pp. 74-79, February 1990.

[14] Schulz, R.P., and B.B. Laios. 1997. "Triggering Tradeoffs for Recording Dynamics." IEEE Computer Applications in Power, pp. 44-49, April 1997.

[15] Hauer, J. 2000. Interim Report on the Model Validation Tests of June 7, 2000 -- Part 1: Oscillatory Dynamics. WSCC Performance Validation Task Force (PVTF) of the Modeling and Validation Work Group, October 26, 2000.

[16] Hauer, J., W.A. Mittelstadt, K.E. Martin, J.W. Burns, and H. Lee, in association with the Disturbance Monitoring Work Group of the Western Electricity Coordination Council. 2007. Integrated Dynamic Information for the Western Power System: WAMS Analysis in 2005. Chapter 14 in the Power System Stability and Control volume of The Electric Power Engineering Handbook, edition 2, L. L. Grigsby ed., CRC Press, Boca Raton, FL, 2007. 


\section{APPENDIX A}

Modal Trends for the WSCC Breakup of August 10, 1996 [4] 


\section{Appendix A. Modal Trends for the WSCC Breakup of August 10, 1996 [4]}

Activity prior to that shown in Figure 1 provided a number of dynamic benchmarks throughout the day of August 10, 1996. Particularly, direct benchmarks occurred around 10:52 PDT, when the Chief Joseph dynamic brake was inserted inadvertently, and when the John Day-Marion line tripped at 14:52. These are shown as Figure 36 and Figure 37. The Prony fit of Figure 38 shows frequency of the North-South mode $^{5}$ at $0.285 \mathrm{~Hz}$. This value is well within the usual range for that time (roughly $0.28 \mathrm{~Hz}$ to $0.33 \mathrm{~Hz}$ ). It is also well above the value observed for a brake test on July 11, 1995. Results for that test showed the AC intertie mode at $0.273 \mathrm{~Hz}$, the lowest value measured accurately during normal operation up to that time, and the damping ratio at 0.11 or $11 \%$. Damping as low as $4 \%$ was regarded as normal for this mode but uncommon. A summary of modal parameters is provided in Table 3Error! Reference source not found..

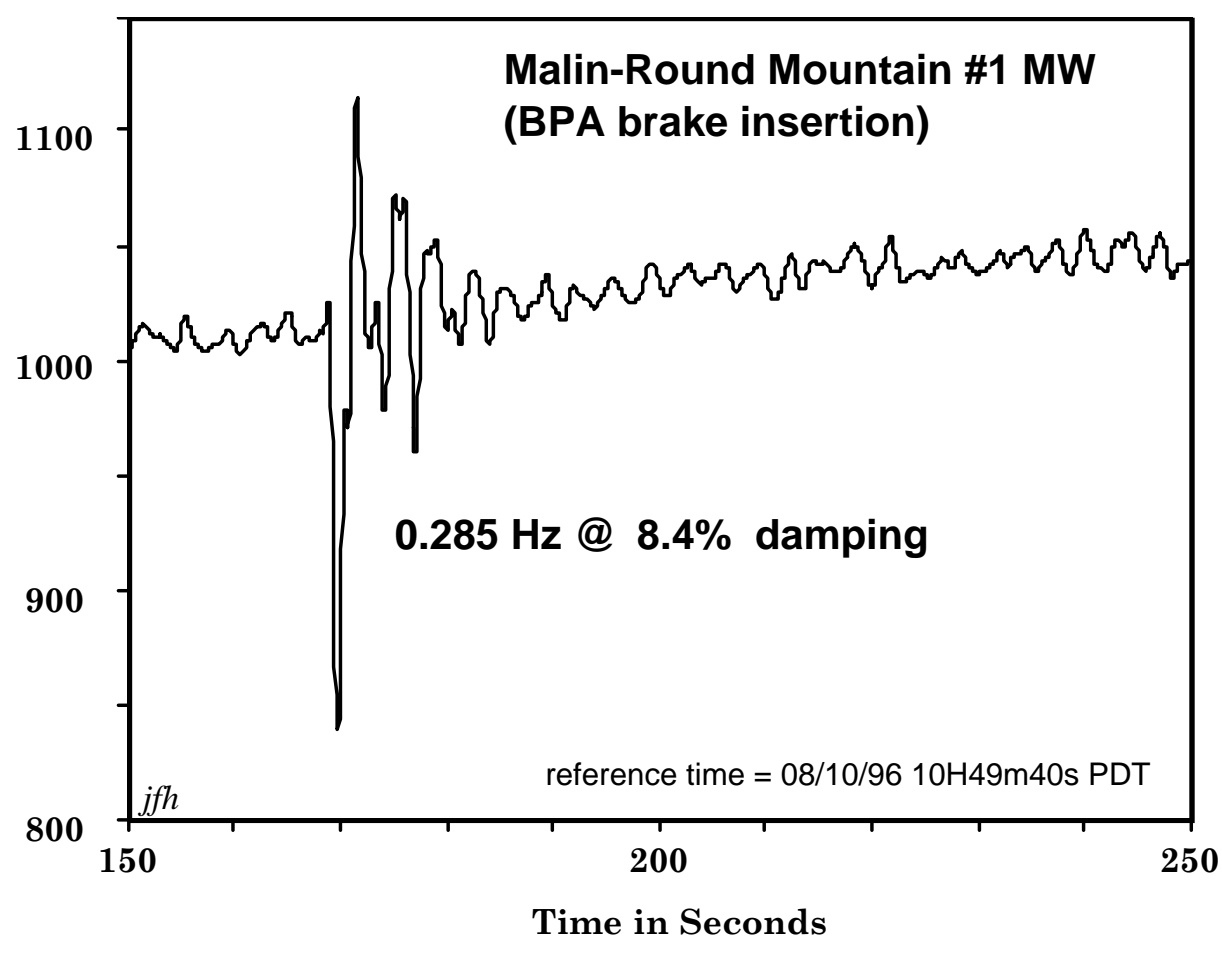

Figure 36. PACI Response to Brake Insertion of 10:52:19 on August 10, 1996

${ }^{5}$ Also called the Pacific AC Intertie (PACI) mode 


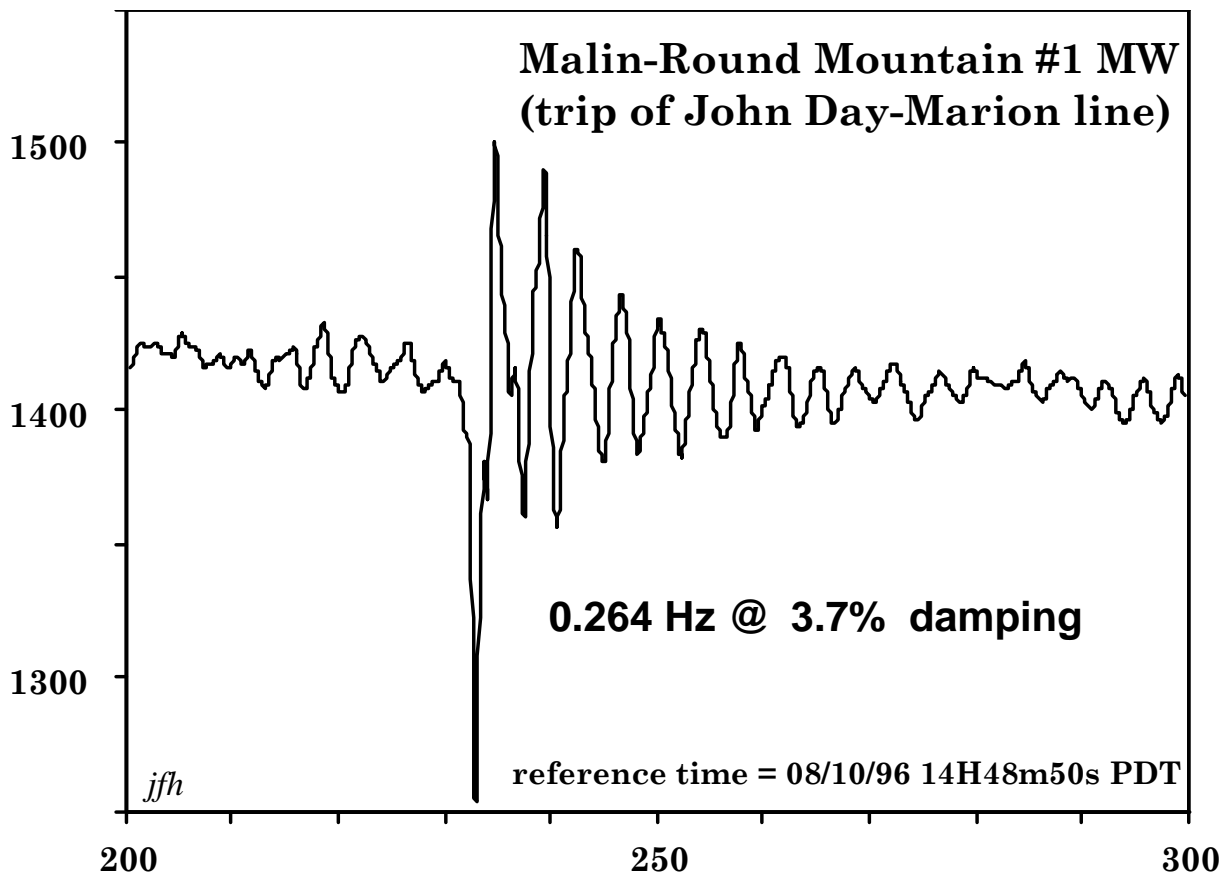

Time in Seconds

Figure 37. PACI Response to Trip of John Day-Marion Line, August 10, 1996 


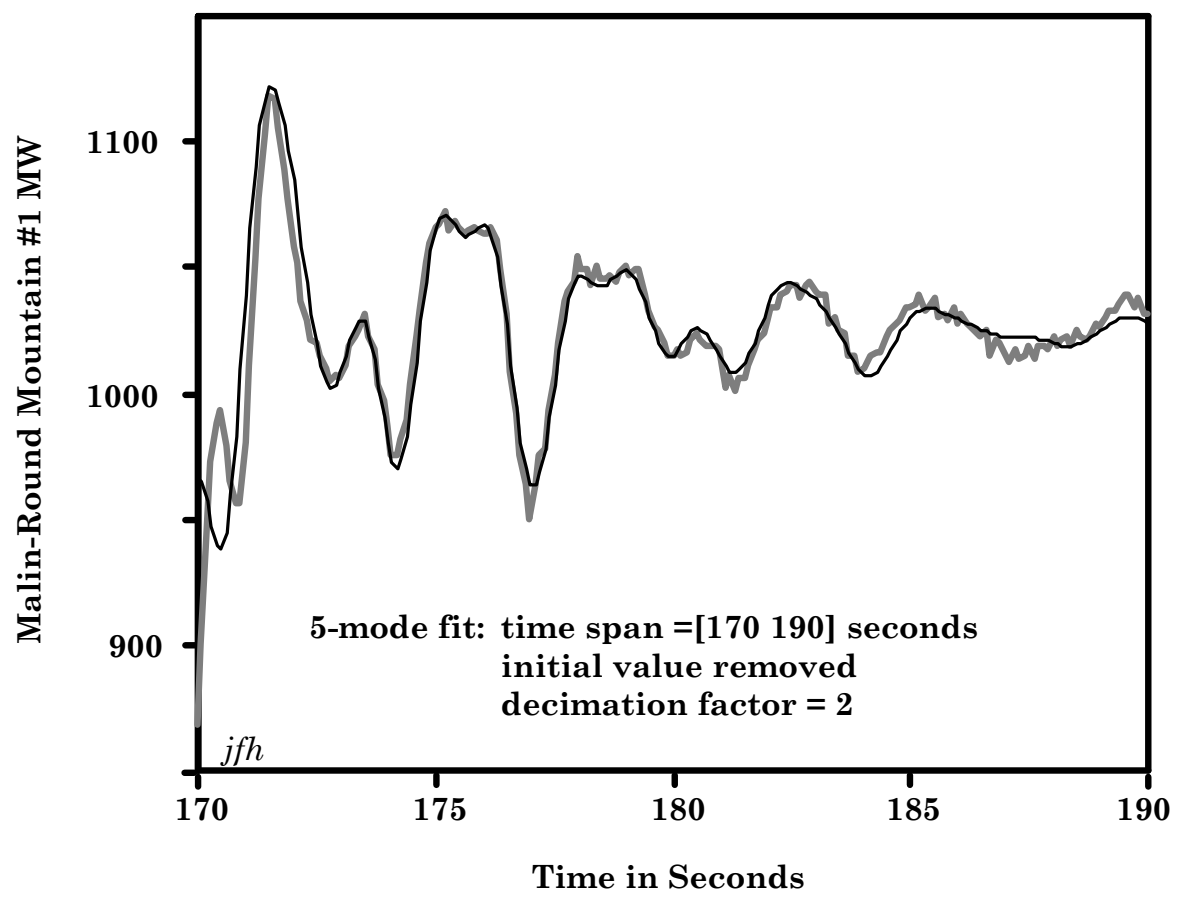

\begin{tabular}{|c|c|c|}
\hline Mode & Frequency in Hz & Damping Ratio \\
\hline trend & (realexponential) & \\
\hline PACI & 0.285 & 0.0844 \\
\hline Alberta & 0.428 & 0.0533 \\
\hline & 0.683 & 0.0694 \\
\hline & 0.734 & 0.0855 \\
\hline
\end{tabular}

Figure 38. Oscillation Modes Visible in the Chief Joseph Brake Insertion at 10:52 PDT on August 10, 1996 
Table 3. Summary of Observed Parameters for the North-South Mode

\begin{tabular}{lcc}
\multicolumn{2}{c}{ Recent Parameters for N-S Mode } \\
Date/Event & Frequency & Damping \\
12/08/92 (Palo Verde trip) & $0.28 \mathrm{~Hz}$ & $7.5 \%$ \\
03/14/93 (Palo Verde trip) & $0.33 \mathrm{~Hz}$ & $4.5 \%$ \\
07/11/95 (brake insertion) & $0.28 \mathrm{~Hz}$ & $10.6 \%$ \\
07/02/96 (system breakup) & $0.22 \mathrm{~Hz}$ & $1.2 \%$
\end{tabular}

N-S Mode on August 10, 1996

Time/Event

10:52:19 (brake insertion)

14:52:37 (John Day-Marion)

15:18 (ringing)

15:42:03 (Keeler-Allston)

15:45 (ringing)

15:47:40 (oscillation startup)

15:48:50 (oscillation finish)

\section{Frequency}

$0.285 \mathrm{~Hz}$

$0.264 \mathrm{~Hz}$

$0.276 \mathrm{~Hz}$

$0.264 \mathrm{~Hz}$

$0.252 \mathrm{~Hz}$

$0.238 \mathrm{~Hz}$

$0.216 \mathrm{~Hz}$

\section{Damping}

$8.4 \%$

$3.7 \%$

$3.5 \%$

$-3.1 \%$

$-6.3 \%$ 